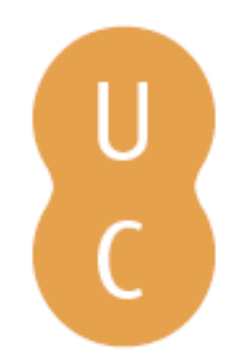

\title{
pommalina
}

\section{Impacto do risco sísmico na resiliência urbana e nas perdas socioeconómicas}

Autor(es): $\quad$ Ferreira, Tiago Miguel; Maio, Rui; Vicente, Romeu

Publicado por: Imprensa da Universidade de Coimbra

URL

persistente:

URI:http://hdl.handle.net/10316.2/38288

DOI:

DOI:http://dx.doi.org/10.14195/9789892610993_8

Accessed : $\quad$ 26-Apr-2023 11:13:16

A navegação consulta e descarregamento dos títulos inseridos nas Bibliotecas Digitais UC Digitalis, UC Pombalina e UC Impactum, pressupõem a aceitação plena e sem reservas dos Termos e Condições de Uso destas Bibliotecas Digitais, disponíveis em https://digitalis.uc.pt/pt-pt/termos.

Conforme exposto nos referidos Termos e Condições de Uso, o descarregamento de títulos de acesso restrito requer uma licença válida de autorização devendo o utilizador aceder ao(s) documento(s) a partir de um endereço de IP da instituição detentora da supramencionada licença.

Ao utilizador é apenas permitido o descarregamento para uso pessoal, pelo que o emprego do(s) título(s) descarregado(s) para outro fim, designadamente comercial, carece de autorização do respetivo autor ou editor da obra.

Na medida em que todas as obras da UC Digitalis se encontram protegidas pelo Código do Direito de Autor e Direitos Conexos e demais legislação aplicável, toda a cópia, parcial ou total, deste documento, nos casos em que é legalmente admitida, deverá conter ou fazer-se acompanhar por este aviso. 


\section{TERRAMOTO DE \\ LISBOA DE 1755}

\section{O QUE APRENDEMOS \\ 260 ANOS DEPOIS?}

LUCIANO LOURENÇO

ÂNGELA SANTOS

(COORDS.)

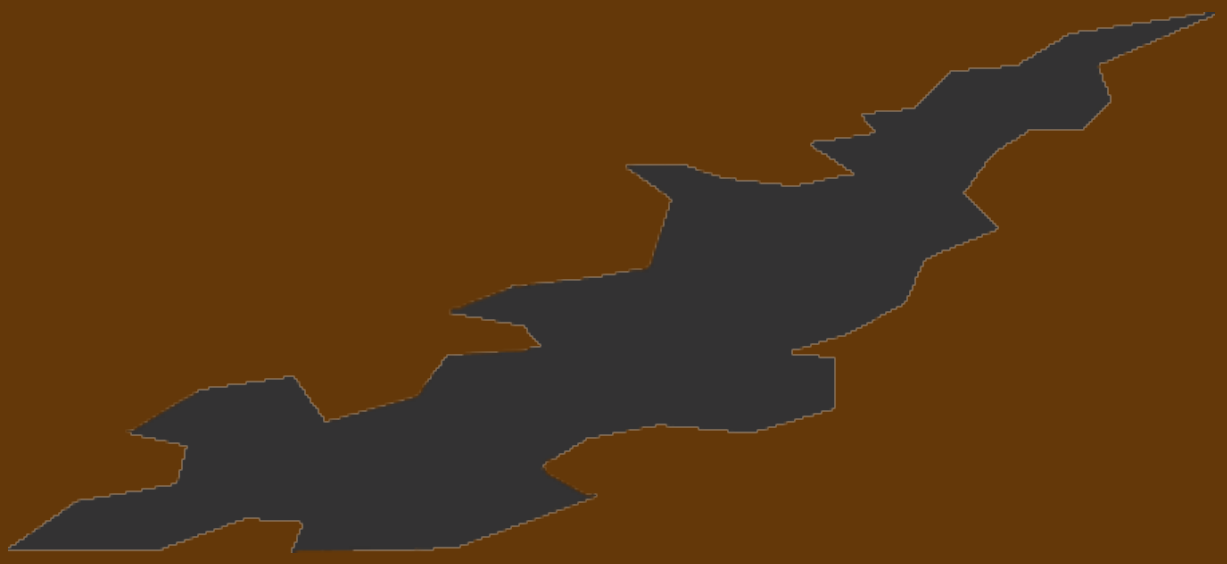

IMPRENSA DA UNIVERSIDADE

DE COIMBRA

COIMBRA

UNIVERSITY

PRESS 


\section{IMPACTO DO RISCO SÍSMICO NA RESILIÊNCIA URBANA E NAS PERDAS SOCIOECONÓMICAS \\ IMPACT OF SEISMIC RISK OVER URBAN RESILIENCE AND SOCIO-ECONOMIC LOSSES}

Tiago Miguel Ferreira

RISCO, Departamento de Engenharia Civil da Universidade de Aveiro tmferreira@ua.pt

Rui Maio

RISCO, Departamento de Engenharia Civil da Universidade de Aveiro ruiamaio@ua.pt

Romeu Vicente

RISCO, Departamento de Engenharia Civil da Universidade de Aveiro romvic@ua.pt

Sumário: O investimento em políticas de mitigação do risco sísmico é considerado fundamental não só na promoção da resiliência urbana e preparação da população para uma situação de catástrofe, mas também no controlo da extensão dos danos provocados no património edificado e assim reduzir ambas as perdas sociais e económicas. Assim, este trabalho tem por objetivo contribuir para a mitigação do impacto de diferentes cenários sísmicos, através da avaliação de diferentes estratégias de reforço, implementadas a parte do núcleo urbano antigo da cidade da Horta.

Palavras-chave: Resiliência urbana; mitigação do risco sísmico; vulnerabilidade sísmica; soluçôes de reforço sísmico; estimativa de perdas 


\begin{abstract}
Investing in disaster risk mitigation policies is a great step towards promoting urban resilience and community preparedness, implicitly limiting damage to the built environment and subsequently reducing both social and economic losses. Hence, this manuscript aims to mitigate the impact of different earthquake scenarios by evaluating the outcome of implementing traditional retrofitting strategies to the building stock of the old city centre of Horta.
\end{abstract}

Keywords: Urban resilience; seismic risk mitigation; seismic vulnerability; seismic retrofit; loss estimation

\title{
Introduçáo
}

O conceito de resiliência urbana é frequentemente definido pela capacidade de certas comunidades expostas a determinados eventos naturais, de suster, resistir e reistituir de forma sustentável a qualidade de vida e condiçôes originais de habitabilidade dessas comunidades. A resiliência urbana para eventos naturais pressupóe assim a aplicação de um conjunto de políticas de frentes distintas, desde a mitigação do risco, preparação das comunidades, capacidade de resposta em condições adversas, recuperação e reconstrução de infraestruturas e edifícios danificados, até à reposição do estado de normalidade naquela comunidade (J. Coaffee, 2008). Uma vez sendo sobejamente reconhecido o enorme impacto que o comportamento estrutural do edificado tem na capacidade resiliente das cidades e das respetivas comunidades, neste trabalho os autores pretendem contribuir para a mitigação do risco sísmico do edificado localizado em centros urbanos antigos, zonas particularmente vulneráveis e de relevante interesse patrimonial. Antes de aprofundarmos a nossa abordagem, é importante referir alguns dos mais bem sucedidos exemplos de estratégias e políticas de mitigação do risco, implementadas recentemente um pouco por todo o mundo. Um dos primeiros passos na implementação de medidas para reduzir o impacto e efeitos adversos decorrentes de eventos naturais, é a identi- 
ficação dos riscos e potenciais ameaças a que determinada comunidade poderá estar sujeita, assim como avaliar a possibilidade de ocorrência em simultâneo de um ou mais eventos. Várias organizaçôes como a GFDRR (Global Facility for Disaster Reduction and Recovery) estão seriamente empenhadas em auxiliar as entidades governamentais e respetivas comunidades localizadas em zonas de elevada perigosidade, através da aplicação de estratégias de disseminação que visam melhorar a perceção, consciencializaçáo e as condiçóes de acesso a informação sobre a exposição social e física a determinado risco. Desta forma, todos os intervenientes encontrar-se-ão melhor capacitados e sensibilizados para o estabelecimento de estratégias de mitigação mais assertivas, decorrentes naturalmente de uma melhor quantificação e estimativa do potencial impacto de determinado desastre natural tanto na economia como na sociedade. Para além disso, estas parcerias colaborativas de partilha de conhecimento e experiências coexistem normalmente muito próximas das entidades governamentais, autoridades de proteção civil e do sector privado, possibilitando a criação e melhoria das atuais leis e políticas locais relativas ao planeamento e ocupação do território, canalizando dessa forma mais fundos para as estratégias de mitigação do risco, atuando simultaneamente como entidades moderadoras num diálogo nem sempre fácil entre as demais partes interessadas (S. Arshad et al., 2013).

Uma vez que a periocidade de ocorrência de fenómenos sísmicos continua a ser revestida de uma grande incerteza e insusceptibilidade, não sendo por isso passíveis de ser controlados nem evitados pelo homem, a preparação e perceção do risco sísmico deverá ser garantida não só através do desenvolvimento e otimização de planos de emergência e contingência que visem proteger e salvar a integridade física e psicológica das comunidades, mas também através da implementação de estratégias de proteção financeira adequadas ao risco de catástrofes, permitindo que até as comunidades mais expostas aos choques económicos e financeiros consigam dar uma resposta mais rápida e equilibrada, melhorando a sua resiliência face a este tipo de desastres naturais. Existem inúmeros exemplos de sucesso que demonstram o impacto positivo do planeamento e gestão do risco de catástrofes na capacidade resiliente das comunidades, como o caso do RHPP (Rural Housing Reconstruction Program), no seguimento do terramoto de Outubro 
de 2005 no norte do Paquistáo, que causou cerca de 73000 mortes e mais de 2.8 milhôes de desalojados (S. Arshad et al., 2013), ou ainda os terramotos do Chile em Fevereiro de 2010 (M. Astroza et al., 2012) e de Christchurch (Nova Zelândia) em Fevereiro de 2011 (M. Mitchelson, 2011). É ainda de destacar o grande terramoto do Japão (Great East Japan Earthquake) em Março de 2011, o primeiro mega-desastre alguma vez registado na história da humanidade, que incluiu a ocorrência de um terramoto e tsunami, procedidos de um acidente numa central nuclear, falha no fornecimento de energia e ainda uma forte perturbação nas cadeias de produção e abastecimento. Causou cerca de 20000 mortes e levou ao colapso mais de 130000 edifícios, tendo danificando severamente outros 270000, com implicaçôes diretas na economia estimadas em 210 bilióes de dólares (F. Ranghieri et al., 2014). Este mega-desastre veio reforçar a importância da consideração dos eventos em cadeia e análise multirriscos nas estratégias de mitigação do risco. De notar que apesar das perdas avultadas, a perceção e preparação da população Japonesa para o risco de terramoto e tsunami é uma das mais evoluídas a nível mundial, demonstrando a imprevisibilidade deste cenário de catástrofe, originado pelo terramoto de magnitude 9.0 e o efeito em cadeia que dele decorreu.

\section{Breve enquadramento}

A sismicidade do território nacional tem sido bastante explorada e debatida ao longo do últimos anos pela comunidade científica, no sentido de alertar as autoridade responsáveis para a necessidade de se tomarem sérias providências e medidas pró-ativas de disseminação direcionadas para a população em geral e de planos de preparação e emergência na eventualidade de um desastre natural. Como agravante, é também conhecido o preocupante estado de degradação, falta de manutenção e elevada vulnerabilidade sísmica de grande parte do edificado antigo e também das estruturas mais recentes, que têm vindo a ser construídas desconsiderando a ação sísmica no seu dimensionamento, um panorama que não é de todo desejável em zonas de sismicidade moderada ou elavada e que 
por isso tem gerado várias açôes de sensibilização por parte da comunidade científica em geral.

Vários estudos desenvolvidos têm alertado para o já referido pobre estado de conservação do edificado antigo, apresentando inclusive algumas medidas corretivas para os problemas estruturais e patologias detetados. Em 2015, Maio et al. (2015a) desenvolveu um estudo muito particular no Bairro Ribeirinho da cidade de Faro, onde numa primeira fase foi efetuado um levantamento e caracterizaçáo construtiva e arquitectónica da zona sob estudo (R. Maio et al., 2015a), com o duplo objetivo de caraterizar e contribuir para o devido reconhecimento público e histórico do património edificado existente, no sentido de potenciar o interesse de possíveis investidores em recuperar e reabilitar um dos bairros mais antigos da cidade de Faro e de grande valor patrimonial. Este trabalho de levantamento e inspeção serviu posteriormente de base para a realização da segunda fase do estudo, que consistiu na avaliação da vulnerabilidade sísmica dos edifícios pertencentes ao Bairro Ribeirinho (R. Maio et al., 2015b), onde a equipa de investigadores envolvida nesta operação, enquadrada no âmbito do projeto FCT URBSIS (Avaliação da Vulnerabilidade e Gestão do Risco Sísmico à Escala Urbana), teve acesso a um conjunto vasto de informação previamente tratada e organizada, acerca dos sistemas e materiais construtivos tradicionais e tipologias existentes. Paralelamente, foram também realizadas açóes de disseminação direcionadas para diferentes públicos alvos, através da realização de um seminário técnico para profissionais e de dois inquéritos, dos quais resultaram importantes indicadores sobre a perceçấo e comunicação do risco sísmico (R. Vicente et al., 2014a). De uma forma geral, os resultados obtidos neste estudo, conduzido a uma escala urbana, permitiu aferir sobre a vulnerabilidade sísmica e o estado de conservação global do edificado, um trabalho de grande pertinência e utilidade, principalmente para as entidades responsáveis pela salvaguarda dos cidadáos e do património, já que, entre outros indicadores, cerca de $20 \%$ dos edifícios localizados neste bairro se encontram em ruína ou devolutos e tantos outros náo apresentam quaisquer tipo de preocupaçóes estruturais sísmicas, sendo o Algarve uma das regiôes de maior sismicidade em Portugal continental. 
O cenário observado no Bairro Ribeirinho da cidade de Faro pode espelhar de certa forma o estado de conservação e a vulnerabilidade do edificado urbano antigo de outras zonas do país de sismicidade moderada a elevada, e em conjunto com o passado histórico importante no que diz respeito a terramotos, tem motivado o desenvolvimento estratégico de algumas das seguintes medidas de mitigação de risco sísmico: o estabelecimento de intervenções e campanhas prioritárias de reforço e reabilitação estrutural do edificado urbano; o desenvolvimento de regimes de seguros para a transferência dos encargos financeiros relativos aos processos de reconstrução das entidades governamentais para o sector privado; a aprovação de legislação adequada para garantir o cumprimento das boas práticas de construção sismo-resistente e ainda o desenvolvimento de planos de emergência a uma escala regional (V. Silva et al., 2014). No entanto, na última década, Portugal tem-se debatido com uma grave crise económico-financeira, que tem condicionado a implementação das medidas anteriores, limitando a resiliência das nossas cidades.

Face à atual conjuntura, os autores têm desenvolvido diversos trabalhos científicos nesta temática, na expectativa de poder contribuir de forma prática na mitigação do risco sísmico no território nacional. Neste sentido, e porque existe uma clara falta de informação sobre os custos adicionais que as práticas tradicionais de reforço sísmico comportam no valor global de uma obra, seja ela de construção ou reabilitação, e os respetivos ganhos em termos de desempenho estrutural, o presente trabalho tem por objetivo estudar a relação do binómio custo-benefício de algumas das medidas mais correntes de reforço sísmico, introduzidas numa metodologia simplificada de avaliação da vulnerabilidade sísmica de edifícios tradicionais de alvenaria de pedra, refutando assim a ideia pré-concebida pela maioria da população em geral, de que as práticas de reforço sísmico são ou demasiado dispendiosas ou mesmo dispensáveis perante a realidade do nosso edificado e respetiva sismicidade do território nacional. 


\section{Mitigaçáo do risco sísmico à escala urbana}

De acordo com Vicente et al. (2014b), os riscos de catástrofe estão associados a determinados eventos de elevada perigosidade cuja probabilidade de ocorrência e potencial para acarretar consequências catastróficas podem ser, de certa forma, estimados. $\mathrm{O}$ conceito de risco sísmico é frequentemente tratado como a combinação entre perigosidade sísmica local, a exposição e a vulnerabilidade intrínseca de um determinado edifício ou conjunto de edifícios. Do ponto de vista da engenharia, a mitigação do risco sísmico está geralmente focada na redução da vulnerabilidade estrutural e sísmica através da implementação de estratégias de reabilitação e reforço sísmico sustentáveis.

Ao nível da gestão do risco, é amplamente reconhecida a necessidade de uma avaliação multidisciplinar que tenha em consideração diferentes cenários de danos e perdas humanas e económicas. Os outputs deverão providenciar elementos importantes no auxílio da tomada de decisão, como a identificação da vulnerabilidade dos elementos expostos a um determinado risco e a sua evolução no tempo, contribuindo assim para uma gestão mais eficaz e sustentável (M-L. Carreño et al., 2007). Neste contexto, a avaliação da vulnerabilidade sísmica de núcleos urbanos antigos como forma de mitigação do risco sísmico, desempenha assim um papel preponderante em virtude do colossal volume de perdas normalmente associadas a estas áreas de acrescido valor patrimonial.

Em muito países, à semelhança de Portugal, o corpo da Proteção Civil é a autoridade responsável pela preparação, coordenação e condução dos planos de emergência nacional para os mais diversos tipos de catástrofes e desastres naturais. De forma a cumprir com a sua missáo, este agente de autoridade deverá definir e hierarquizar as áreas mais vulneráveis, exercitando a sua capacidade de resposta em campo através de simulacros e também a sua sensibilidade às questóes de foro logístico e recursos humanos necessários para cada tipo de cenário (X. Goula, et al., 2006). No entanto, e de acordo com (T. Ferreira et al., 2013), esta gestão do risco em áreas urbanas é muitas vezes realizada sem uma ferramenta adequada de planeamento, dificultando a tomada de decisão dos técnicos e agentes de autoridade que assim não conseguem construir uma visão global da área sob estudo, podendo inclusive comprometer a eficácia e o arran- 
que de estratégias mitigação de riscos. Torna-se assim necessário o uso de ferramentas multiusos interligadas com bases de dados em Sistemas de Integração Geográfica (SIG), através do qual é possível realizar análises espacialmente integradas do edificado e gerir diferentes tipos de dados, desde as características intrínsecas dos edifícios, informação proveniente de fichas de inspeção, ou ainda, por exemplo, outputs relativos à vulnerabilidade sísmica e cenários de danos e perdas de cada um desses edifícios. Este tipo de ferramenta apresenta-se assim como uma mais valia não só para o desenvolvimento de estratégias de reforço sísmico e análises custo-benefício, mas também para suportar a implementação dos planos de emergência desenvolvidos pela Proteção Civil a nível local (F. Neves et al., 2012).

No seguimento das consideraçóes enunciadas no parágrafo anterior, os outputs discutidos ao longo deste trabalho serão apresentados sob a forma de mapas trabalhados através da versão comercial do programa SIG ArcGis ${ }^{\circledast} 10.2$ (Esri, 2012). Estes mapas cruzam informação gráfica georreferenciada com uma base de dados onde estão reunidas as mais importantes características estruturais dos edifícios avaliados. Todas as rotinas foram programadas em Phython ${ }^{\odot}$ e compiladas em Visual Basic (uma linguagem de programação compatível) num ambiente Microsoft Windows ${ }^{\oplus} 7$. Vários módulos foram desenvolvidos para diferentes tarefas, incluindo a avaliação da vulnerabilidade, a estimativa de danos e perdas e ainda custos de reabilitação para diferentes intensidades macrossísmicas, permitindo a construção de múltiplos cenários de dano e perdas com reduzido esforço computacional e de recursos.

\section{Avaliação da vulnerabilidade sísmica do núcleo urbano antigo da cidade da Horta}

\section{A aplicação da metodologia do índice de vulnerabilidade}

O presente caso de estudo diz respeito à avaliação da vulnerabilidade sísmica no núcleo urbano antigo da cidade da Horta, ilha do Faial (arquipélago dos Açores). É importante referir que esta ilha foi uma das mais atingidas na sequência do 
terramoto dos Açores de 9 de Julho de 1998, que deixou um manifesto rasto de destruiçáo por toda a ilha, tendo conduzido cerca de $70 \%$ do edificado à ruína, e afetado diretamente mais de 5000 pessoas (8 mortos, 150 feridos e 1500 desalojados). O processo de reconstruçáo desta e das restantes ilhas afetadas por este terramoto foi conduzido pela Sociedade de Promoçáo e Reabilitaçáo da Habitação e Infraestruturas (SPRHI) e durou cerca de dez anos, permitindo a recolha de uma quantidade de informação sobre dano pós-terramoto sem precedentes no nosso país, que foi posteriormente organizada e arquivada em 2007 pela Secretaria Regional da Habitação e Equipamentos (SRHE), que dirigiu esta iniciativa (F. Neves et al., 2012). A qualidade e a singularidade da base de dados motivou o desenvolvimento de inúmeros trabalhos científicos ao longo dos últimos anos. Apesar do livre acesso à referida base de dados ter-nos sido providenciado, foram ainda realizadas algumas inspeçôes e levantamentos in situ prospetadas no âmbito do já referido projeto FCT URBSIS, de forma a complementar alguma dessa informação e a interpretar a evoluçáo e o processo diacrónico resultante das intervençôes de reabilitaçáo implementadas desde 1998. Apesar do nível de dano verificado no edificado urbano da cidade da Horta, classificado com uma intensidade macrossísmica $\mathrm{I}_{\mathrm{EMS}-98}=\mathrm{V} / \mathrm{VI}$ (G. Zonno et al., 2010), não ter sido táo severo como no edificado em ambiente rural, esta acabou por ser a zona selecionada como caso de estudo no presente trabalho, dada a sua significância patrimonial. É importante ainda referir que os autores consideraram a avaliação do edificado existente à data do terramoto de 1998, portanto, imediatamente antes de se darem início os trabalhos de reconstrução, reabilitação e reforço sísmico, condição que daqui para a frente será designada por SR ("sem” reforço).

Neste sentido, a vulnerabilidade sísmica do núcleo urbano antigo da cidade da Horta foi avaliado através da aplicação da metodologia do índice de vulnerabilidade desenvolvido por Vicente (2008), baseado na abordagem da metodologia Italiana GNDT II (GNDT, 1994), e que tem vindo a ser utilizada nos últimos anos na avaliação da vulnerabilidade sísmica de núcleos urbanos antigos de cidades como Coimbra, Seixal e Faro (R. Vicente et al., 2011; T. Ferreira et al., 2013; R. Maio et al., 2015). À semelhança das dificuldades enfrentadas nos anteriores casos de estudo, nomeadamente ao nível da inspe- 
ção e levantamento estrutural dos edifícios e da logística associada a este tipo de açôes, os autores acabaram por atuar em dois níveis de avaliação distintos. Assim, os 313 edifícios pertencentes à área delimitada sob estudo foram divididos em quatro grupos em funçáo do nível de detalhe da informação disponível. Um primeiro grupo, composto por 50 edifícios avaliados de forma detalhada (Avaliaçáo Detalhada), foi avaliado tendo em conta as plantas de arquitetura e plantas estruturais, reportagens fotográficas pós-terramoto e outros relatórios relacionados com o respetivo processo de reabilitação (especificações técnicas e orçamentos), permitindo recolher de um forma geral, toda a informação necessária à avaliaçáo de todos os parâmetros integrantes da referida metodologia. Um segundo grupo formado por 142 edifícios foi apenas avaliado com recurso a uma inspeção pelo exterior do edifício (Avaliaçáo não-detalhada). Um terceiro grupo composto por 93 edifícios de betáo armado não foi incluído neste estudo, uma vez que a metodologia utilizada foi apenas desenvolvida para a avaliação da vulnerabilidade sísmica de edifícios de alvenaria. Finalmente, um quarto grupo foi definido para agrupar 28 edifícios também eles não avaliados neste estudo, uma vez se tratarem de edifícios religiosos ou governamentais (singulares), ou ainda edifícios que se encontram num estado de pré-ruína ou sujeitos a processos de reabilitação. Desta forma, o de índice de vulnerabilidade médio foi estimado através da assemblagem dos dois primeiros grupos, avaliação essa que daqui para a frente será designada por Avaliação global.

A metodologia de avaliaçáo sísmica do índice de vulnerabilidade aqui aplicada, classificada como uma técnica híbrida, apropriada para uma avaliação a larga escala de edifícios de alvenaria (G. Calvi et al., 2006), compreende a determinaçáo de um índice de vulnerabilidade sísmica, $I_{v}^{*}$, para cada edifício, calculado através da média ponderada de 14 parâmetros, onde cada um deles avalia um determinado aspeto relacionado com a resposta sísmica do edifício, distribuídos em quatro classes de vulnerabilidade crescente, $C_{v i}$, de A a $\mathrm{D}$ (R. Vicente et al., 2011):

$$
I_{v}^{*}=\sum_{i=1}^{14} C_{v i} \times p_{i}
$$


Posteriormente, um peso variável $p_{i}$, é atribuído a cada parâmetro com base na opiniáo de especialistas, assumindo valores desde 0.50 para os parâmetros menos importantes em termos de vulnerabilidade estrutural, até 1.50 para aqueles considerados mais importantes. $\mathrm{O}$ valor inicial de $I_{v}^{*}$, que pode variar portanto entre 0 e 650 , é posteriormente normalizado passando a variar entre 0 e 100 , designado por $I_{v}$, para facilitar a sua própria leitura e ainda a sua comparação com a estimativa de danos com base em diferentes escalas macrossísmicas (G. Grünthal, 1998) ou perdas. De acordo com a Tabela I, estes 14 parâmetros estáo agrupados em quatro grandes grupos por forma a destacar a sua a importância relativa e diferenças na resposta sísmica global do edifício.

Apesar da definiçấo do peso de cada um dos parâmetros poder apresentar naturalmente alguma incerteza, os autores acreditam que, com base nas experiências

TABELA I - Metodologia do índice de vulnerabilidade (Vicente, 2008).

TABLE I - Vulnerability index methodology (Vicente, 2008).

\begin{tabular}{|c|c|c|c|c|c|c|c|}
\hline \multirow{2}{*}{$\begin{array}{c}\text { Parâmetros } \\
\text { por grupo }\end{array}$} & \multicolumn{5}{|c|}{ Classe $\mathrm{C}_{\mathrm{vi}}$} & \multirow{2}{*}{ Peso pi } & \multirow{2}{*}{$\begin{array}{l}\text { Peso relati- } \\
\text { vo sobre } I_{v}\end{array}$} \\
\hline & & A & B & $\mathrm{C}$ & $\mathrm{D}$ & & \\
\hline \multicolumn{7}{|c|}{ 1. Sistema construtivo } & \multirow{7}{*}{$46 / 100$} \\
\hline \multicolumn{2}{|c|}{ P1 Tipo do sistema resistente } & 0 & 5 & 20 & 50 & 0.75 & \\
\hline \multicolumn{2}{|c|}{ P2 Qualidade do sistema resistente } & 0 & 5 & 20 & 50 & 1.00 & \\
\hline \multicolumn{2}{|c|}{ P3 Resistência convencional } & 0 & 5 & 20 & 50 & 1.50 & \\
\hline \multicolumn{2}{|c|}{ P4 Distância máxima entre paredes } & 0 & 5 & 20 & 50 & 0.50 & \\
\hline \multicolumn{2}{|c|}{ P5 Altura do edifício } & 0 & 5 & 20 & 50 & 1.50 & \\
\hline \multicolumn{2}{|c|}{ P6 Posição do edifício e fundações } & 0 & 5 & 20 & 50 & 0.75 & \\
\hline \multicolumn{2}{|c|}{ 2. Irregularidades e interaçóes } & & & & & & \multirow{4}{*}{$27 / 100$} \\
\hline \multicolumn{2}{|c|}{ P7 Localização e interação } & 0 & 5 & 20 & 50 & 1.50 & \\
\hline \multicolumn{2}{|c|}{ P8 Irregularidade em planta } & 0 & 5 & 20 & 50 & 0.75 & \\
\hline \multicolumn{2}{|c|}{ P9 Irregularidade em altura } & 0 & 5 & 20 & 50 & 0.75 & \\
\hline \multicolumn{2}{|c|}{ 3. Pavimentos e cobertura } & & & & & & \multirow{4}{*}{$15 / 100$} \\
\hline \multicolumn{2}{|c|}{ P10 Desalinhamento de aberturas } & 0 & 5 & 20 & 50 & 0.50 & \\
\hline \multicolumn{2}{|c|}{ P11 Diafragmas horizontais } & 0 & 5 & 20 & 50 & 1.00 & \\
\hline \multicolumn{2}{|c|}{ P12 Tipo de cobertura } & 0 & 5 & 20 & 50 & 1.00 & \\
\hline \multicolumn{3}{|c|}{ 4. Estado de conservação e outros elementos } & & & & & \multirow{3}{*}{$12 / 100$} \\
\hline \multicolumn{2}{|c|}{ P13 Danos estruturais identificados } & 0 & 5 & 20 & 50 & 1.00 & \\
\hline \multicolumn{2}{|c|}{ P14 Elementos não estruturais } & 0 & 5 & 20 & 50 & 0.50 & \\
\hline
\end{tabular}


anteriores, se a inspeçáo dos edifícios for conduzida de uma forma detalhada e o mais precisa possível, esta metodologia pode ser considerada robusta, com uma incerteza associada à atribuiçáo das classes de vulnerabilidade de cada parâmetro relativamente baixa (R. Vicente et al., 2011; R. Maio et al., 2015). De acordo com a explicação anterior, numa primeira fase foram avaliados os 50 edifícios pertencentes ao primeiro grupo (Avaliação detalhada). Posteriormente, numa segunda fase, foram avaliados os 142 edifícios avaliados de forma não detalhada (Avaliação não-detalhada), usando como ponto de partida os valores médios obtidos na Avaliação detalhada, assumindo as propriedades da alvenaria homogéneas em toda a zona de estudo. Partindo deste princípio, o valor médio do índice de vulnerabilidade sísmica calculado na Avaliação detalhada foi adoptado como indicador tipológico de vulnerabilidade na Avaliação não-detalhada, sendo posteriormente afetado pelos coeficientes dos parâmetros modificadores (T. Ferreira et al., 2013).

A classificação desses parâmetros modificadores influencia o índice de vulnerabilidade de cada um dos edifícios pertencentes à Avaliação não-detalhada através da soma de cada um dos respetivos coeficientes, definidos na TABela II. Desta forma, o índice de vulnerabilidade da Avaliação não-detalhada, $\overline{\overline{I_{v}}}$, é definido de acordo com a equação:

$$
\overline{\overline{I_{v}}}=\overline{I_{v}}+\sum \Delta I_{v}
$$

onde $\bar{T}_{v}$ é o valor médio do índice de vulnerabilidade calculado na avaliação detalhada e $\Sigma \Delta I_{v}$ é a soma dos coeficientes modificadores para a respetiva classe atribuída. É importante notar que esta estratégia é apenas válida se a Avaliação detalhada compreender um número significativo de edifícios e uma única tipologia construtiva da zona sob estudo. A seguinte equação demonstra como foram calculados os coeficientes relativos a cada uma das classes dos parâmetro modificadores:

$$
\frac{p_{i}}{\sum_{i=1}^{6} p_{i}} \times\left(C_{v i}-\overline{C_{v i}}\right)
$$

onde $p_{i}$ representa o peso atribuído a cada parâmetro modificador $i, \sum_{\mathrm{i}=1}^{6} p_{i}$ representa a soma de cada um dos pesos pi, $\mathrm{C}_{v i}$ é a classe de vulnerabilidade 
TABELA II - Coeficientes dos parâmetros modificadores.

TABLE II - Vulnerability index modifier factors and scores.

\begin{tabular}{|l|c|c|c|c|}
\hline \multirow{2}{*}{ Parâmetros modificadores } & \multicolumn{4}{c|}{ Classe $\mathbf{C}_{\mathbf{v i}}$} \\
\cline { 2 - 6 } & A & B & C & D \\
\hline P4 Distância máxima entre paredes & -0.31 & 0.00 & 0.94 & 2.81 \\
\hline P5 Altura do edifício & -0.94 & 0.00 & 2.81 & 8.44 \\
\hline P7 Localização e interação & -0.94 & 0.00 & 2.81 & 8.44 \\
\hline P9 Irregularidade em altura & -0.47 & 0.00 & 1.41 & 4.22 \\
\hline P10 Desalinhamento de aberturas & -0.31 & 0.00 & 0.94 & 2.81 \\
\hline P14 Elementos não estruturais & -1.25 & -0.94 & 0.00 & 1.88 \\
\hline
\end{tabular}

de cada um dos coeficientes e $\overline{C_{v i}}$ é a classe de vulnerabilidade média obtida para cada parâmetro na Avaliação detalhada.

Com a aplicação da metodologia do índice de vulnerabilidade aos 50 edifícios da Avaliação detalhada, foi obtido um valor do índice de vulnerabilidade médio, igual 26.32, com desvio padrão $\sigma_{I_{v}}$, igual a 9.73. Posteriormente, a introdução da Avaliação não-detalhada na referida metodologia levou à obtenção de um valor médio do índice global de vulnerabilidade sísmica (Avaliação global), $I_{v \text { global }}$ igual a 26.55, ao qual está associado um desvio padrão $\sigma I_{v_{\text {global }}}$, de 5.45 . Os valores máximos e mínimos dos índices de vulnerabilidade, $I_{v}$, obtidos com a Avaliação detalhada do edificado do núcleo urbano da cidade da Horta foram 55.00 e 10.96, respetivamente. Os histogramas e curvas de distribuição normal resultantes da aplicação faseada desta metodologia são apresentados na fig. 1 .

O mapeamento e distribuição dos índices de vulnerabilidade $I_{v}$, obtidos para a Avaliação global será apresentado e discutido mais à frente na fig. 7 (a), de forma a poder comparar a condição original $S R$ com os diferentes cenários de reforço sísmico.

É importante notar também que os resultados aqui obtidos para esta condição original $S R$ podem dizer-se bem ajustados às características do edificado e às fragilidades avaliadas e registadas pelas fotografias anexadas aos respetivos relatórios de dano, aquando do terramoto de 1998, que vêm assim confirmar a robustez e o sentido prático desta metodologia. 


\section{A aplicação de soluçóes tradicionais de reforço sísmico}

A proteção da vida e integridade física da população é um dos principais objetivos das açóes de reforço e reabilitaçáo sísmica. Em muitos casos as exigências colocadas aos edifícios existentes em termos de desempenho na salvaguarda da vida humana são difíceis de alcançar apenas recorrendo a pequenas intervençóes estruturais. Assim, o reforço sísmico em edifícios existentes é considerado não sustentável em situaçóes em que o capital necessário associado às soluçóes de reforço exceda o custo inicial do edifício, ou ainda quando estes se encontram num estado avançado de degradação ou pré-ruína. Ainda assim, os custos associados com operaçóes de demoliçáo, redireccionamento de resíduos e a reconstrução de um novo edifício deveráo determinar a viabilidade de cada projeto de reforço sísmico ou reabilitação. Para além disso, outros assunto legais deverão ser equacionados quando por exemplo, a segurança de um determinado edifício está condicionada pelo estado de conservação dos edifícios adjacentes, tal como acontece nos edifícios dispostos em banda. Reforçar ou reabilitar sismicamente um edifício em banda sem intervir nos edifícios adjacentes, quando estes não cumprem os requisitos mínimos de segurança sísmica, acaba por se tornar contraproducente (J. Bothara et al., 2011). As seguintes estratégias de reforço têm vindo a ser apontadas por Bothara et al. (2011) como as que melhor relaçâo custo-benefício apresentam na melhoria da segurança estrutural e sísmica de edifícios de alvenaria: i) melhorar

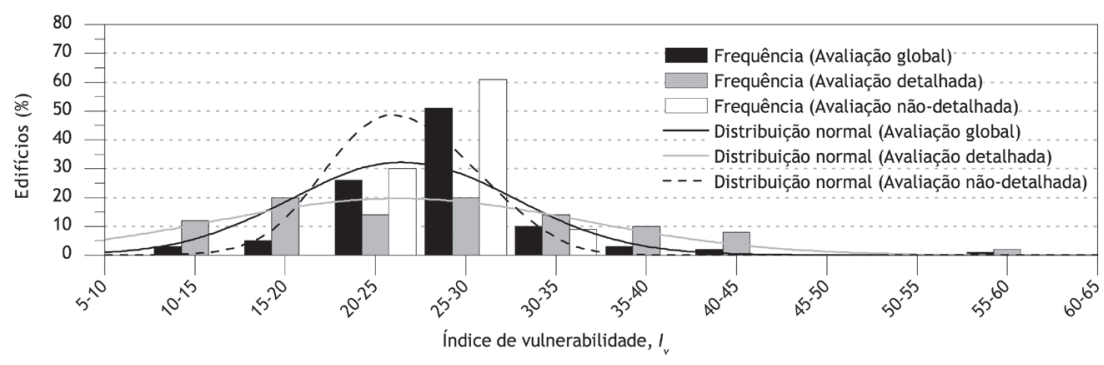

Fig. 1 - Histogramas e curvas de distribuição normal de cada uma das fases de avaliação (Avaliação detalhada e Avaliação não-detalhada) e da Avaliação global, relativas à condição original $S R$ do edificado.

Fig. 1 - Histograms and best-fit normal distribution curves for each assessment phase (Detailed and Non-detailed assessment) and for the Overall assessment, both relative to the SR original building condition. 
a integridade global do edifício garantindo um comportamento sísmico em caixa (do inglês "box-like behaviour"); ii) melhorar a resistência no plano e fora do plano das paredes resistentes de alvenaria e o comportamento dos diafragmas horizontais e ainda iii) reforço ao nível das fundaçóes, uma estratégia de difícil aplicabilidade e por isso pouco viável na maioria dos casos.

Uma vez que a demolição e substituição generalizada dos edifícios tradicionais de alvenaria não devem ser vistas com estratégias a considerar, dadas as implicaçóes de natureza económica, cultural, histórica e patrimonial, as estratégias de reforço sísmico adoptadas neste estudo, desenvolvidas pelo Laboratório Regional de Engenharia Civil dos Açores (LREC) em parceria com uma vasta equipa de técnicos e investigadores das áreas da sismologia, engenharia sísmica e engenharia civil (A. Costa et al., 2008; C. Oliveira et al., 1990), de acordo com as recomendaçóes definidas no processo de reconstrução do Faial (E. Carvalho et al., 1998) na sequência dos terramotos dos Açores de 1990 e 1998, têm na sua génese essa preocupação em manter a integridade construtiva e arquitectónica dos edifícios. Neste sentido, são aqui analisadas seis soluçóes de reforço de grau de intrusividade e custo crescentes, de $S 1$ a $S 6$, agrupadas em três pacotes de reforço acumulativos, de $P R 1$ a $P R 3$, apresentadas na seguinte TABELA III.

TABELA III - Soluções de reforço sísmico adoptadas.

TABLE III - Seismic retrofitting solutions adopted.

\begin{tabular}{|c|c|c|c|}
\hline Pacote de reforço, $P R$ & $\begin{array}{l}\text { Solução } \\
\text { de reforço }\end{array}$ & Descrição & $\begin{array}{c}\text { Custo estimado } \\
€ / \mathrm{m}^{2}\end{array}$ \\
\hline \multirow{4}{*}{$P R 1=S 1+S 2+S 3+S 4$} & $S 1$ & $\begin{array}{l}\text { Reforço da ligação entre paredes } \\
\text { resistentes com tirantes }\end{array}$ & \multirow{4}{*}{35} \\
\hline & $S 2$ & $\begin{array}{l}\text { Aumento da rigidez com taruga- } \\
\text { mento e contra-soalho }\end{array}$ & \\
\hline & S3 & $\begin{array}{l}\text { Reforço da ligação entre paredes } \\
\text { e diafragmas horizontais }\end{array}$ & \\
\hline & S4 & $\begin{array}{l}\text { Reforço da ligação entre paredes } \\
\text { e cobertura com tirantes }\end{array}$ & \\
\hline$P R 2=P R 1+S 5$ & S5 & $\begin{array}{l}\text { Reforço da ligação entre pare- } \\
\text { des e cobertura com cinta de } \\
\text { coroamento }\end{array}$ & 100 \\
\hline$P R 3=P R 2+S 6$ & $S 6$ & $\begin{array}{l}\text { Consolidação e reforço das } \\
\text { paredes de alvenaria com re- } \\
\text { boco armado }\end{array}$ & 230 \\
\hline
\end{tabular}


A solução de reforço da ligação entre paredes resistentes através da introduçáo de tirantes, designada por $S 1$, é uma das mais antigas e eficazes soluçóes de reforço sísmico e também uma das mais utilizadas internacionalmente. Com diâmetros compreendidos normalmente entre os 16 e os $20 \mathrm{~mm}$ (J. Bothara et al., 2011), estes tirantes de aço são aplicados horizontalmente ao nível dos pavimentos (no caso da soluçáo S1), ou ainda ao nível da cobertura (solução S4), dispostos com um espaçamento variável em função do vão e da tipologia da parede resistente e devidamente ancorados, tal como ilustrado na fig. 2 (a), adaptada de Carvalho et al. (1998) e D’Ayala e Speranza (2002).

Esta solução é duplamente vantajosa pois para além de permitir aumentar a rigidez dos diafragmas horizontais, por natureza extremamente flexíveis, reforça ainda a ligaçáo entre as paredes fachada e as paredes de frontal. Por outro lado, a predominância de diafragmas flexíveis, comprovada pela equipa durante o trabalho de campo, aliada ao avançado estado de degradação global ou parcial dos mesmos (nomeadamente ao nível das ligaçôes e apoios), torna de certa forma imperativa a consideraçáo de uma soluçáo de reforço sísmico e estrutural a este nível, representada pela solução $S 2$. Esta solução, ilustrada na fig. 2 (b), incluiu a substituição total ou parcial de todos os elementos de madeira deteriorados e ainda duas medidas para o aumento de rigidez: a instalaçấo de tarugos de madeira de $75 \mathrm{~mm}$ dispostos na diagonal entre as vigas de madeira do pavimento, com ancoragem realizada através de varóes roscados de $10 \mathrm{~mm}$ e chapas quinadas de $3 \mathrm{~mm}$ de espessura e a instalaçáo de contra-soalho, disposto perpendicularmente e devidamente pregado/ligado ao soalho existente. Ainda no que diz respeito às soluçóes integrantes do pacote de reforço $P R 1$, o reforço da ligaçáo entre as paredes resistentes e os diafragmas horizontais (S3) foi idealizado pela introdução de chapas quinadas de $3 \mathrm{~mm}$ devidamente ancoradas às paredes por meio de varóes roscados, tal como ilustrado na fig. 2 (c). Finalmente a solução de reforço $S 4$, respeitante ao reforço da ligação entre as paredes e a cobertura, compreende o uso da mesma técnica da solução $S 1$, com a aplicação de tirantes realizada desta vez ao nível da cobertura.

O pacote de reforço $P R 2$, tal como foi referido anteriormente, para além de envolver a aplicação das soluçôes reforço anteriores respeitantes ao pacote $P R 1$, pressupôe ainda a introdução de vigas cintas (perimetrais) em betão armado 

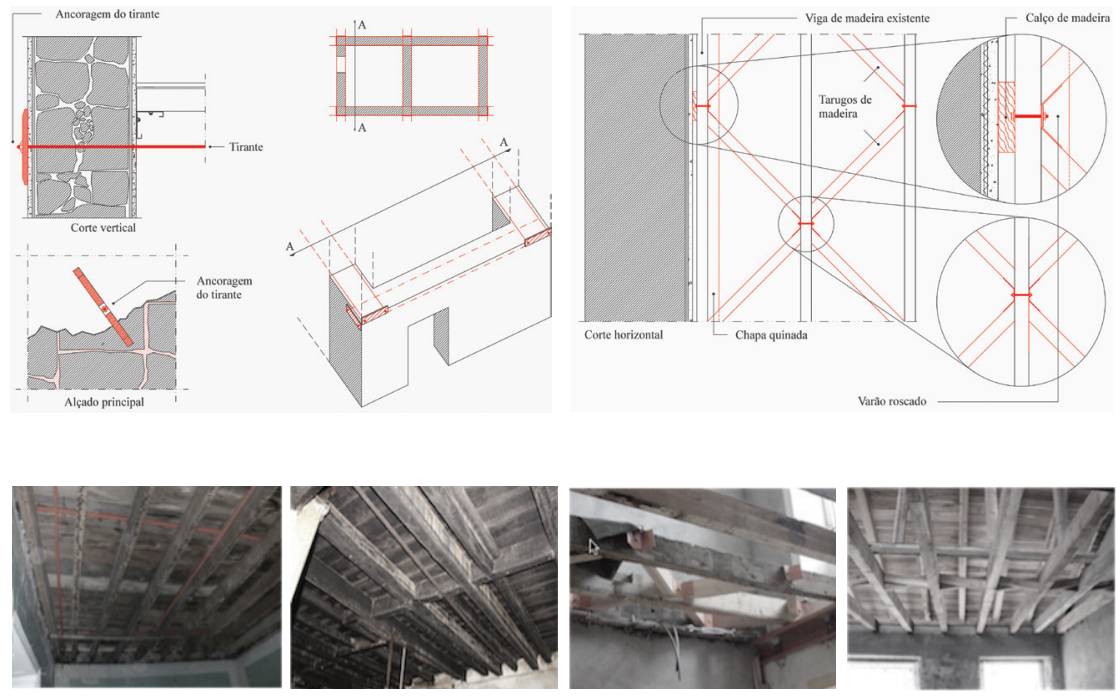

(a) Solução de reforço $S 1$

(b) Solução de reforço $S 2$
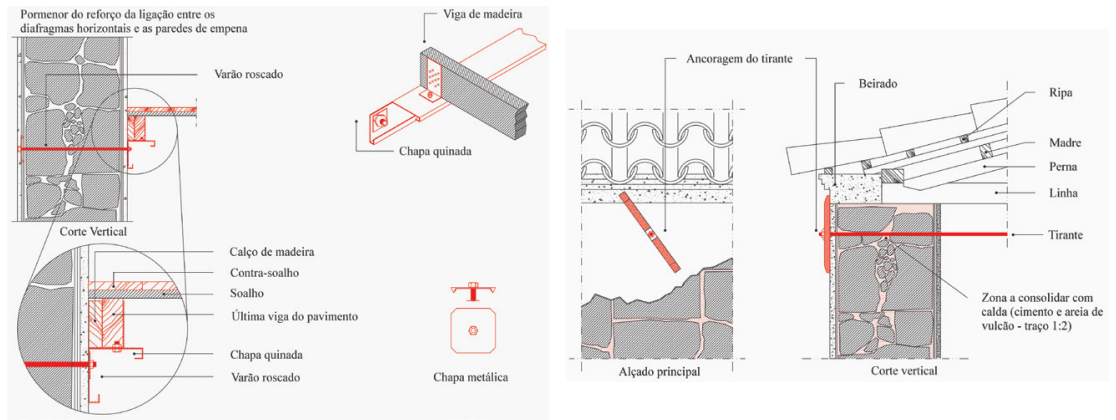
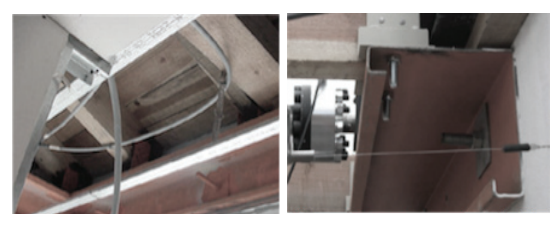

(d) Solução de reforço $S 4$
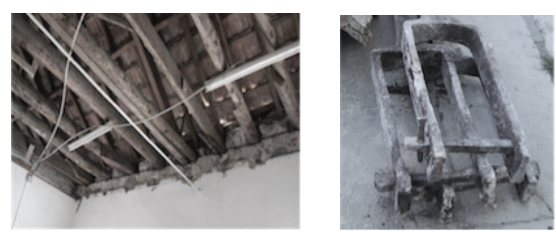

(c) Solução de reforço $S 3$

Fig. 2 - Pormenores das soluçóes de reforço implementadas no pacote PR1. Fig. 2 - Details of retrofitting actions of package PR1. 
no coroamento das paredes resistentes de alvenaria (S5), vigas essas realizadas com $4 \varphi 10 \mathrm{~mm}$ (armadura longitudinal) e $\varphi 6 / / .20 \mathrm{~mm}$ (estribos), reforçando assim o referido box-like behaviour dos edifícios e ainda a ligação entre essas paredes e estrutura da cobertura (ver fig. 3).
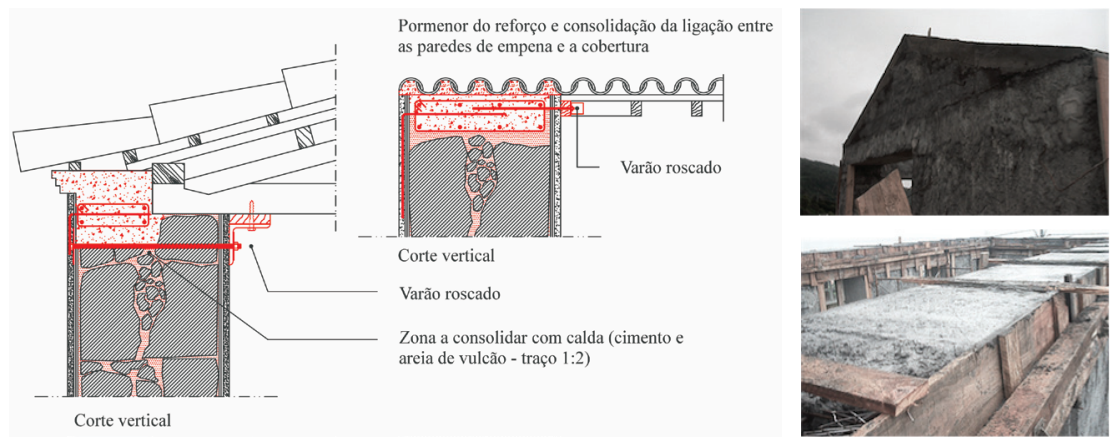

Fig. 3 - Pormenores das solução de reforço $S 5$ implementada no pacote $P R 2$.

Fig. 3 - Details of retrofitting solution $S 5$ implemented in package PR2.

Por último, o pacote de reforço $P R 3$, compreende a aplicação de todas as seis soluçóes de reforço consideradas, diferenciando-se do pacote $P R 2$, apenas pela introdução da solução $S 6$, relativa à consolidação e reforço das paredes de alvenaria com reboco armado (ver fig. 4), de acordo com as especificaçóes avançadas por Costa (2002).
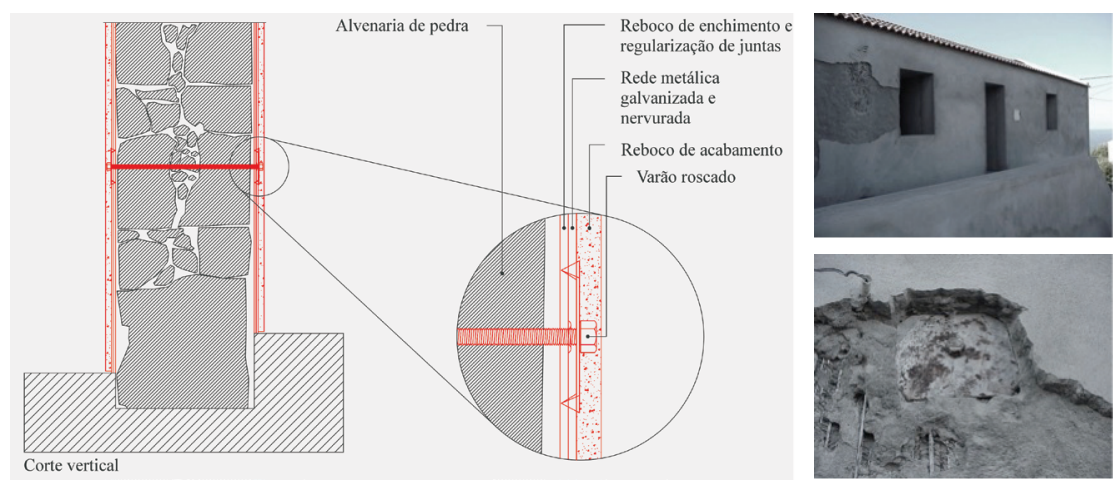

Fig. 4 - Pormenores das solução de reforço $S 6$ implementada no pacote PR3.

Fig. 4 - Details of retrofitting solution $S 6$ implemented in package PR3. 


\section{O reflexo de cada soluçáo de reforço na metodologia do índice de vulnerabilidade}

No seguimento da seçáo anterior, aqui serão tecidas algumas consideraçóes sobre a influência efetiva que as seis soluçôes de reforço consideradas apresentam no cálculo do índice de vulnerabilidade segundo a metodologia simplificada de avaliação da vulnerabilidade sísmica descrita anteriormente e considerada neste estudo. De acordo com a Tabela IV, cada uma das soluçóes de reforço contribuiu diretamente para a melhoria gradual do índice de vulnerabilidade , através da melhoria das classes de vulnerabilidade $C_{v i}$, nomeadamente dos parâmetros P1, P2, P3, P11, P12 e P13. É importante notar uma vez mais que estas soluções foram implementadas de forma cumulativa, de $S 1$ até $S 6$. Assim, todas as soluções de reforço, exceção feita para $S 4$ e $S 6$, implicaram a atribuição direta de uma determinada classe de vulnerabilidade para o respetivo parâmetro em questão, classe essa que foi assim assumida igual em todos os edifícios avaliados.

Convém referir que, em casos muito pontuais de edifícios que à data do terramoto de 1998 já se apresentavam munidos com uma ou mais soluçôes de reforço equiparáveis, a sua classe de vulnerabilidade não sofreu naturalmente

TABELA IV - Influência de cada solução de reforço sobre o índice de vulnerabilidade , $\mathrm{I}_{v}$. TABLE IV - Influence of each retrofitting solution over the vulnerability index value, $\mathrm{I}_{v}$.

\begin{tabular}{|c|c|c|c|}
\hline $\begin{array}{l}\text { Soluçáo de } \\
\text { reforço }\end{array}$ & Descriçáo & Parâmetro & $\begin{array}{c}\text { Classe } \\
\mathrm{C}_{\mathrm{vi}}\end{array}$ \\
\hline$S 1$ & $\begin{array}{l}\text { Reforço da ligaçáo entre paredes resistentes com ti- } \\
\text { rantes }\end{array}$ & P1 & B \\
\hline$S 2$ & Aumento da rigidez com tarugamento e contra-soalho & P11 & A \\
\hline S3 & $\begin{array}{l}\text { Reforço da ligação entre paredes e diafragmas hori- } \\
\text { zontais }\end{array}$ & P1 & A \\
\hline$S 4$ & $\begin{array}{l}\text { Reforço da ligação entre paredes e cobertura com } \\
\text { tirantes }\end{array}$ & P12 & +1 \\
\hline S5 & $\begin{array}{l}\text { Reforço da ligaçáo entre paredes e cobertura com } \\
\text { cintas de coroamento }\end{array}$ & P12 & A \\
\hline$S 6$ & $\begin{array}{l}\text { Consolidação e reforço das paredes de alvenaria com } \\
\text { reboco armado }\end{array}$ & $\begin{array}{l}\text { P2 } \\
P 3 \\
P 13\end{array}$ & $\begin{array}{l}A \\
\tau_{0} \\
A\end{array}$ \\
\hline
\end{tabular}


qualquer alteração. A solução de reforço $S 4$ foi implementada na metodologia melhorando em apenas uma classe a classe de vulnerabilidade do parâmetro P12, originalmente atribuída para a condição original $S R$ do edificado.

Já a implementação da solução de reforço $S 6$, que influiu diretamente sobre o parâmetro $\mathrm{P} 3$, requer maior atenção. Em primeiro lugar convém realçar que em ambiente urbano, exemplo do presente caso de estudo, a tipologia de alvenaria de pedra observada na maioria dos edifícios, difere bastante daquela encontrada em ambiente rural, nomeadamente no que diz respeito à qualidade e tipologia construtiva da alvenaria, propriedades mecânicas da pedra, qualidade de embricamento e das juntas, por exemplo.

Tal como demonstrado na TABela V, para a avaliaçáo do parâmetro P3 dos edifícios do núcleo urbano antigo da cidade da Horta, foram consideradas duas tipologias distintas de alvenaria de pedra, baseadas na correspondência entre as tipologias de alvenaria definidas pela Norma Italiana NTC (2008) e a classificação tipológica definida por Costa (2002) para os edifícios em ambiente rural e urbano. Assim, a soluçáo de reforço $S 6$ teve reflexo náo só ao nível da atribuição de uma classe de vulnerabilidade A para os parâmetros P2 e P13, mas também na melhoria do valor da resistência ao corte da alvenaria $\tau_{0}$, valor estimado de acordo com a Norma Italiana NTC (2008) e necessário no cálculo da resistência convencional (P3).

\section{Análise comparativa}

Os resultados obtidos para os valores do índice de vulnerabilidade sísmica do edificado urbano na condição original $S R$, apresentados na fig. 6 (a), refletem em geral a boa qualidade construtiva e baixa vulnerabilidade sísmica do edificado e estão em conformidade com os relatórios de dano consultados que relatam o baixo impacto que o terramoto de 1998 teve neste núcleo urbano antigo da cidade da Horta, em termos de dano estrutural. Esta baixa vulnerabilidade generalizada deve-se principalmente à geometria e alinhamentos favoráveis da maioria do edificado avaliado, onde os parâmetros P4, P6, P7, P9 e P10 se apresentam como os mais influentes, tal como demonstrado pela fig. 5 (a). 
TABELA V - Correspondência entre a classificação tipológica de Costa (2002) e da Norma Italiana NTC (2008).

TABLE V-Correspondence between Costa (2002) and Italian code NTC (2008) typological classification of masonry.

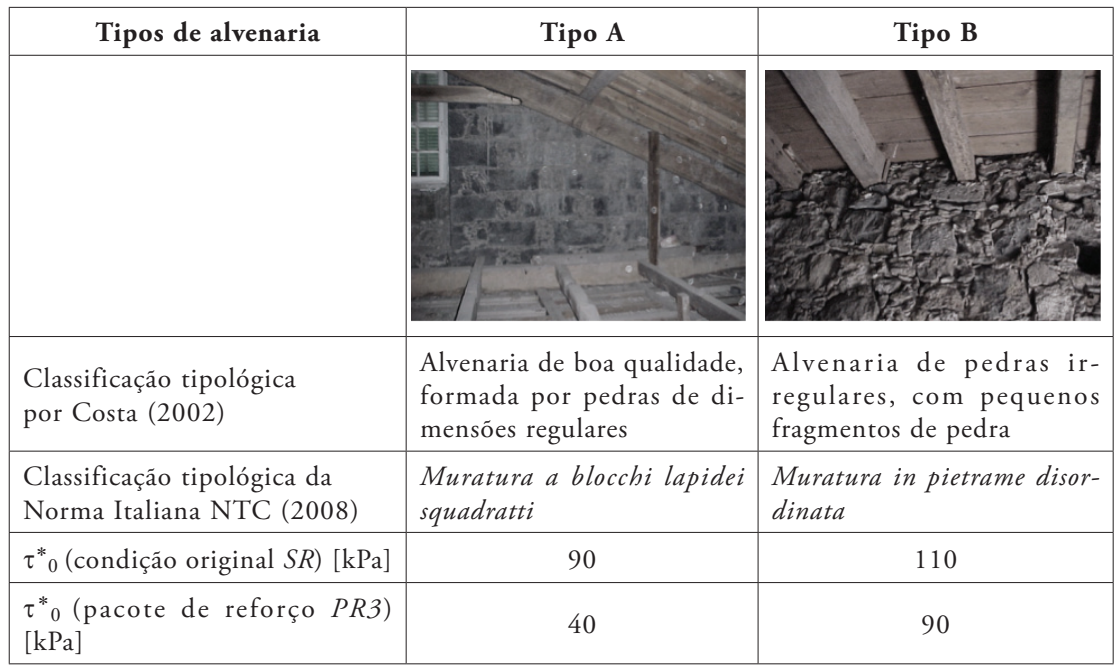

Nesta seção serão apresentados e discutidos os mais relevantes outputs que permitirão estabelecer a comparação a vários níveis entre os três pacotes de reforço estudados. Assim, a primeira análise, apresentada na fig. 5, é feita para avaliar a influência que cada classe de vulnerabilidade $C_{v i}$ tem em cada parâmetro, isto para cada uma das condiçốes estudadas ( $S R, P R 1, P R 2$ e $P R 3)$, permitindo compreender o impacto gradual e efetivo que cada pacote de reforço teve no cálculo do índice de vulnerabilidade sísmica, $\mathrm{I}_{V_{\text {global }}}$.

A aplicação da metodologia considerando o pacote de reforço PR1 conduziu a uma redução do valor médio do índice global de vulnerabilidade sísmica, $\mathrm{I}_{V_{\text {global }}}$, em cerca de $18.9 \%$. Subsequentemente, com a introdução do pacote de reforço $P R 2$, e uma vez mais quando comparada com a situação não reforçada $(S R)$, esta redução subiu ligeiramente para uma percentagem em torno dos $23.1 \%$. Finalmente, considerando o pacote de reforço $P R 3$ (o qual inclui os pacotes de reforço anteriores $P R 1$ e $P R 2)$, o valor médio do índice de vulnerabilidade sísmica foi reduzido em 51.7\%. A fig. 6 apresenta o mapeamento da vulnerabilidade sísmica dos edifícios em situação não reforçada $(S R)$, enquanto a fig. 7 apresenta o 




(a) Condiçẫo original $S R$

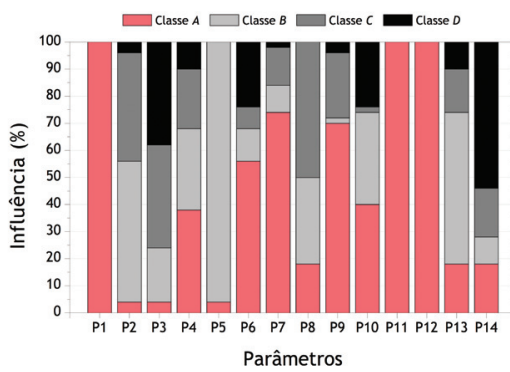

(c) Pacote de reforço PR2

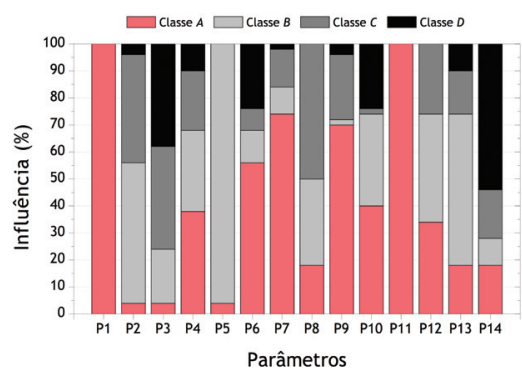

(b) Pacote de reforço PRI

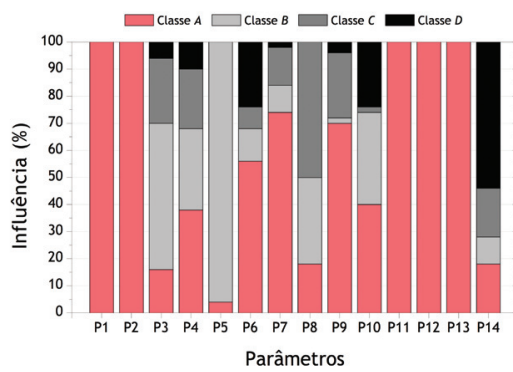

(d) Pacote de reforço PR3

Fig. 5 - Influência global de cada classe de vulnerabilidade sobre $\mathrm{I}_{V_{\text {global }}}$.

Fig. 5 - Global influence of the each vulnerability class over $I_{V_{\text {global }}}$

mesmo mapeamento, desta feita tendo em conta a inclusão de todas as soluçóes de reforço analisadas (correspondente ao pacote $P R 3$ ). Os resultados obtidos em termos do índice vulnerabilidade sísmica encontram-se compilados na TABELA VI. Na mesma tabela apresentam-se ainda as reduçôes em termos percentuais obtidas com a aplicação de cada um dos pacotes de reforço, sempre em relação à condição original do edifício não reforçado $(S R)$.

\section{Cenários de dano e avaliação de perdas}

Tal como discutido anteriormente, a avaliação de perdas desempenha um papel fundamental na implementação de medidas de gestão e planeamento 
TABELA VI - Valores de índice de vulnerabilidade e respectivas reduçôes em termos percentuais.

TABLE VI - Vulnerability index values and reduction values.

\begin{tabular}{|c|c|c|c|c|c|}
\hline \multirow{2}{*}{$\begin{array}{c}\text { Condiçáo do } \\
\text { edificado }\end{array}$} & \multicolumn{2}{|c|}{ Avaliaçáo detalhada } & \multicolumn{2}{c|}{ Avaliaçáo global } & Reduçáo \\
\cline { 2 - 6 } & $\overline{I_{v}}$ & $\sigma_{\bar{I}_{v}}$ & $\bar{I}_{v_{\text {global }}}$ & $\sigma_{\bar{I}_{\text {global }}}$ & $\mathbf{( \% )}$ \\
\hline$S R$ & 26.32 & 9.73 & 26.55 & 5.45 & - \\
\hline$P R 1$ & 21.30 & 7.64 & 21.52 & 4.52 & 18.9 \\
\hline$P R 2$ & 20.19 & 7.18 & 20.41 & 4.32 & 23.1 \\
\hline$P R 3$ & 12.61 & 4.72 & 12.84 & 3.34 & 51.7 \\
\hline
\end{tabular}

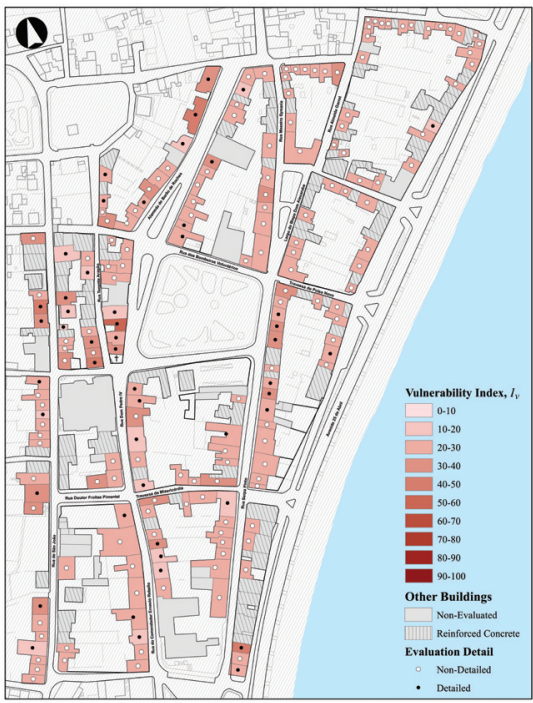

(a)

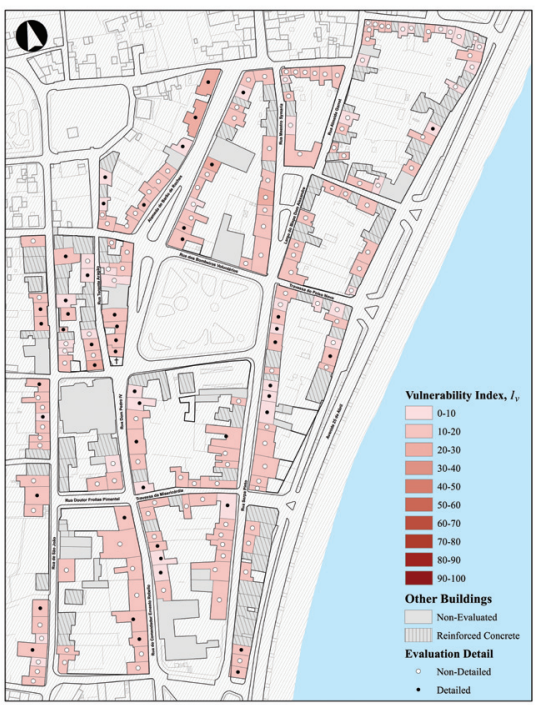

(b)

Fig. 6 - Mapeamento do índice de vulnerabilidade, , considerado: (a) a situaçáo original $S R$ e (b) a aplicação do pacote de reforço $P R 3$.

Fig. 6 - Vulnerability index, , obtained for: (a) SR condition and (b) PR3 retrofitting package.

urbano e de reforço do edificado, permitindo o confronto entre os custos associados à implementação dessas medidas e o seu retorno em termos financeiros e humanos (D. D’Ayala et al., 1997). Assim, esta secção apresenta os resultados de perdas estimadas para diferentes cenários de dano calculados para diferentes intensidades macrossísmicas, $I_{E M S-98}$. De acordo com Nunes (2008), durante a 
segunda metade do século XX as intensidades macrossísmicas máximas registadas no arquipélago dos Açores variaram entre $I_{E M S-98}=$ VII e VIII, para os sismos de 1952 (São Miguel), 1964 (São Jorge), 1973 (Pico) e 1988 (São Miguel), tendo sido ainda registada uma intensidade máxima de IX durante as crises sísmicas de 1958, 1980 e 1998. De entre os vários métodos descritos na literatura para estimar perdas em função da probabilidade de ocorrência de um certo grau de dano, optou-se neste trabalho pela construção de cenários de dano baseados em distribuiçôes probabilísticas globais, através dos valores obtidos para o índice de vulnerabilidade sísmica, $I_{V_{\text {global }}}$, para as diferentes condiçóes aqui analisadas (SR, PR1, PR2 e PR3). Os modelos de distribuição de dano dependem inevitavelmente dos graus de dano físico, compreendendo ainda a definição das correlaçóes entre a probabilidade de excedência de um certo nível de dano e a probabilidade da ocorrência de um determinado fenómeno de perda (por exemplo a probabilidade de colapso ou de inutilização de um edifício devido à falta de condiçóes de segurança estrutural, a probabilidade de ocorrência de mortos ou feridos graves, etc.). Desta forma, e com base nos outputs obtidos para a avaliação da vulnerabilidade sísmica do edificado é possível estimar graus de dano médio, $\mu_{D}$, para diferentes intensidades macrossísmicas. Para isso, Bernardini et al. (2007) propôs uma expressão analítica que corelaciona a intensidade macrossísmica com o grau de dano médio $\left(0 \leq \mu_{\mathrm{D}} \leq 5\right)$ em função da vulnerabilidade sísmica:

$$
\mu_{D}=2.5 \times\left[1+\tanh \left(\frac{I+6.25 \times V-13.1}{Q}\right)\right] ; \quad 0 \leq \mu_{D} \leq 5
$$

onde $I$ representa a intensidade macrossísmica de acordo com a Escala Macrossísmica Europeia (EMS-98), $V$ é o índice de vulnerabilidade utilizada na metodologia macrossísmica e que se relaciona um valor de índice de vulnerabilidade sísmica, $I_{v}$, através da equação abaixo, e $Q$ é um factor de ductilidade que tem em conta a ductilidade da tipologia construtiva em análise (variável entre 1 e 4). Seguindo o que é recomendado por Vicente et al. (2011) e Ferreira et al. (2013), foi adoptado aqui um valor de $Q$ igual a 3.0. 


$$
V=0.592+0.0057 \times I_{V}
$$

A fig. 7 (a) apresenta as curvas de vulnerabilidade obtidas a partir do valor médio do índice global de vulnerabilidade sísmica, $\mathrm{I}_{V_{\text {global }}}$, considerando cada uma das condiçôes do edificado analisadas, e para intensidades macrossísmicas entre V e XII. Adicionalmente, a fig. 7 (b) e (c) apresenta dois exemplos de distribuiçôes de grau de dano médio obtidas através da distribuição probabilística beta para intensidades macrossísmicas $I_{E M S-98}=\mathrm{IX}$ e $I_{E M S-98}=\mathrm{X}$, a qual corresponde à máxima intensidade histórica registada na cidade da Horta (J. Nunes, 2008). Importa referir ainda que a variância da distribuição beta foi definida com base nos seguintes parâmetros: $t=8, a=0$ e $b=5$.

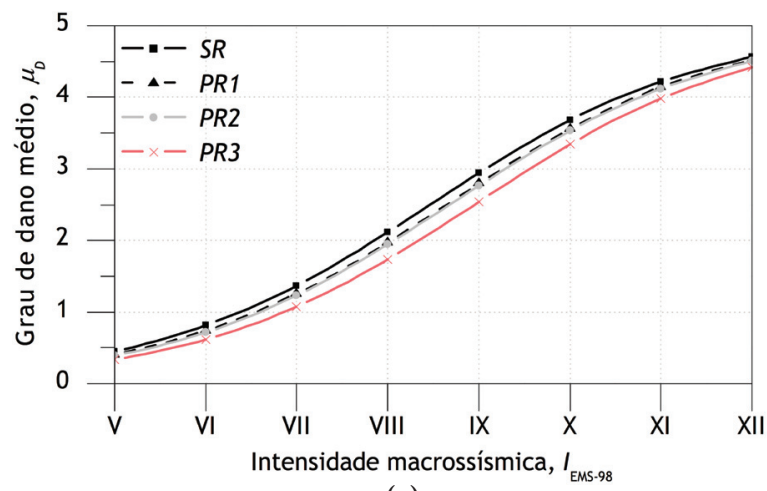

(a)

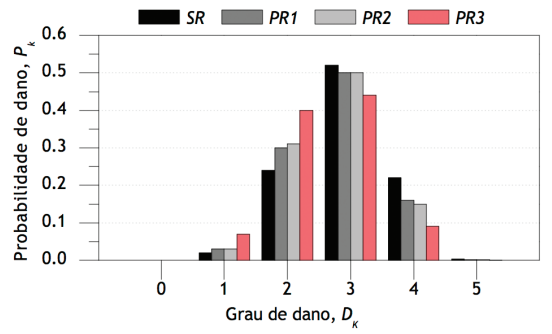

(b)

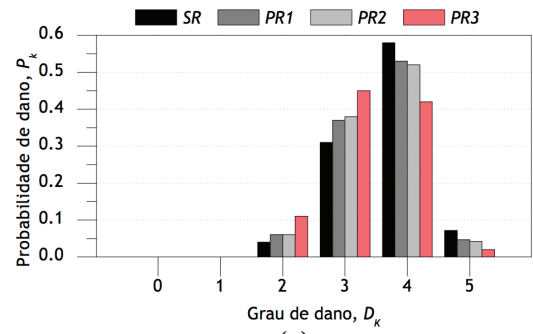

(c)

Fig. 7 - Curvas de vulnerabilidade obtidas para cada uma das condições analisadas (a) e correspondentes distribuiçóes probabilísticas de dano, $P_{k}$, obtidas para cada grau de dano, $\mathrm{D}_{k}$, para valores de intensidade macrossísmica de $I_{E M S-98}=I X$ (b) e $I_{E M S-98}=X$ (c).

Fig. 7 - Vulnerability curves for the considered building conditions (a) and the corresponding damage probabilities, $P_{k}$, obtained for each damage grade, $D_{k}$, for macroseismic intensities of $I_{E M S-98}=I X(b)$ and $I_{E M S-98}=X(c)$. 
Tal como foi já mencionado, a utilização de Sistemas de Informação Geográfica (SIG) possibilita a representação espacial das distribuiçóes globais de dano para o edificado em análise, permitindo a identificação das áreas e dos edifícios mais vulneráveis, o que, para fins de gestão urbana e de definição de estratégias de ação e planeamento, representa uma mais valia importante. A fig. 8 (a) e (b) apresenta os cenários de dano obtidos para eventos sísmicos de intensidades $I_{E M S-98}=\mathrm{IX}$ e $I_{E M S-98}=\mathrm{X}$, para as condiçōes $S R$ e $P R 3$, respectivamente.

Globalmente, os danos estimados para os edifícios sem reforço $(S R)$ variaram entre 2.49 e 3.69 e entre 3.30 e 4.23 para cenários sísmicos correspondentes às

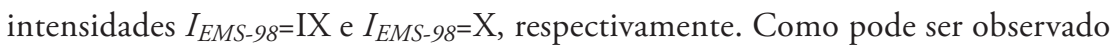
na fig. 8 (b), com a aplicação o pacote de reforço PR3, os valores obtidos em termos de grau de dano médio reduziram substancialmente, para valores a variar entre 2.30 e 2.88 e entre 3.12 e 3.63 (mínimo e máximo) para intensidades macrossísmicas de $I_{E M S-98}=\mathrm{IX}$ e $I_{E M S-98}=\mathrm{X}$, respectivamente.

Tendo por base estes resultados, é pertinente notar que alguns autores (L. Pagnini et al., 2011; R. Vicente et al., 2011; T. Ferreira et al., 2013) referem que edifícios com valores de índice de vulnerabilidade igual ou superior a 45, isto é, edifícios para os quais é expectável a ocorrência de danos severos $\left(3 \leq \mu_{\mathrm{D}} \leq 4\right)$ e de fenómenos de colapso localizado $\left(\mu_{D}>4\right)$, devem ser sujeitos a uma reavaliaçấo com recurso a uma metodologia de análise mais detalhada. $\mathrm{O}$ modelo de estimativa de dano utilizado neste trabalho é baseado em graus de dano que relacionam a probabilidade de excedência de um certo nível de dano e a probabilidade de colapso e perda de funcionalidade. Apoiados em observação de dano, a abordagem aqui aplicada foi proposta pelo Servizio Sísmico Nazionale (SSN) com base nos trabalhos de Bramerini et al. (1995). Esta metodologia envolve a análise de informaçáo associada à probabilidade de inutilização dos edifícios para açôes sísmica de intensidade baixa e moderada.

Tal como destacado por Maio et al. (2015a), apesar deste tipo de açóes produzirem baixos níveis de dano estrutural e não-estrutural, valores de dano médio mais elevados encontram-se normalmente associados a probabilidades de colapso, também elas, mais elevadas. Assim, a probabilidade de um certo nível de dano ser excedido é utilizada na estimativa de dano afectada por um factor 

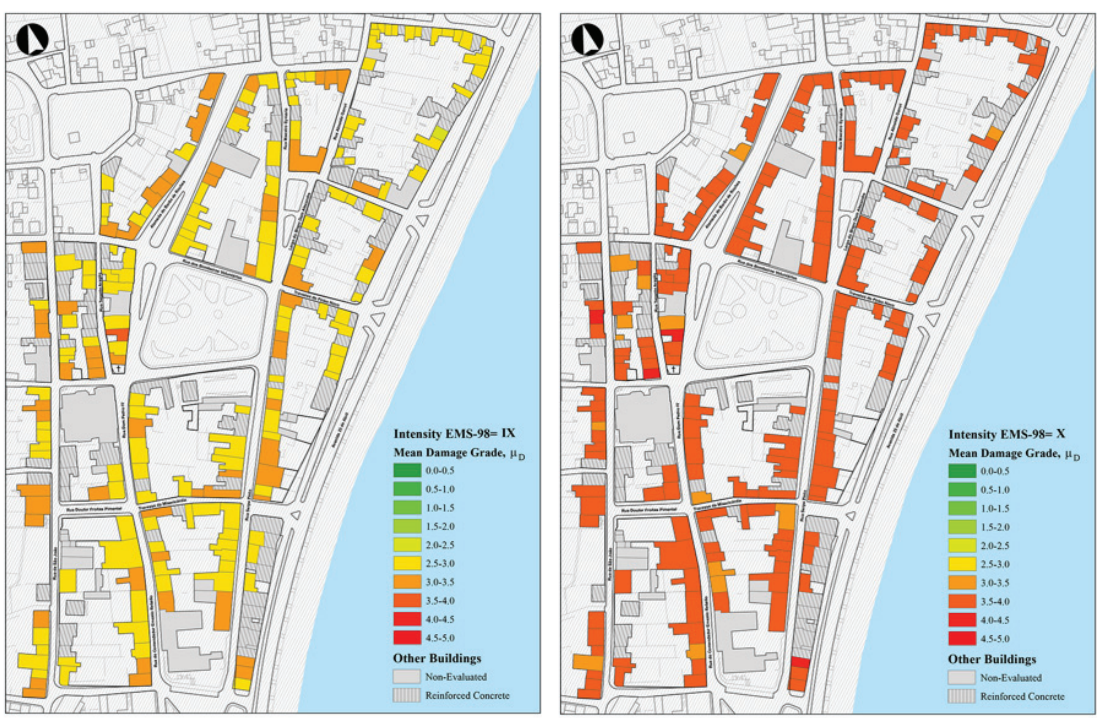

(a) Distribuiçôes de dano considerando a condiçấo $S R$, obtidas para intensidades $I_{E M S-98}=\mathrm{IX}$ e $I_{E M S-98}=\mathrm{X}$
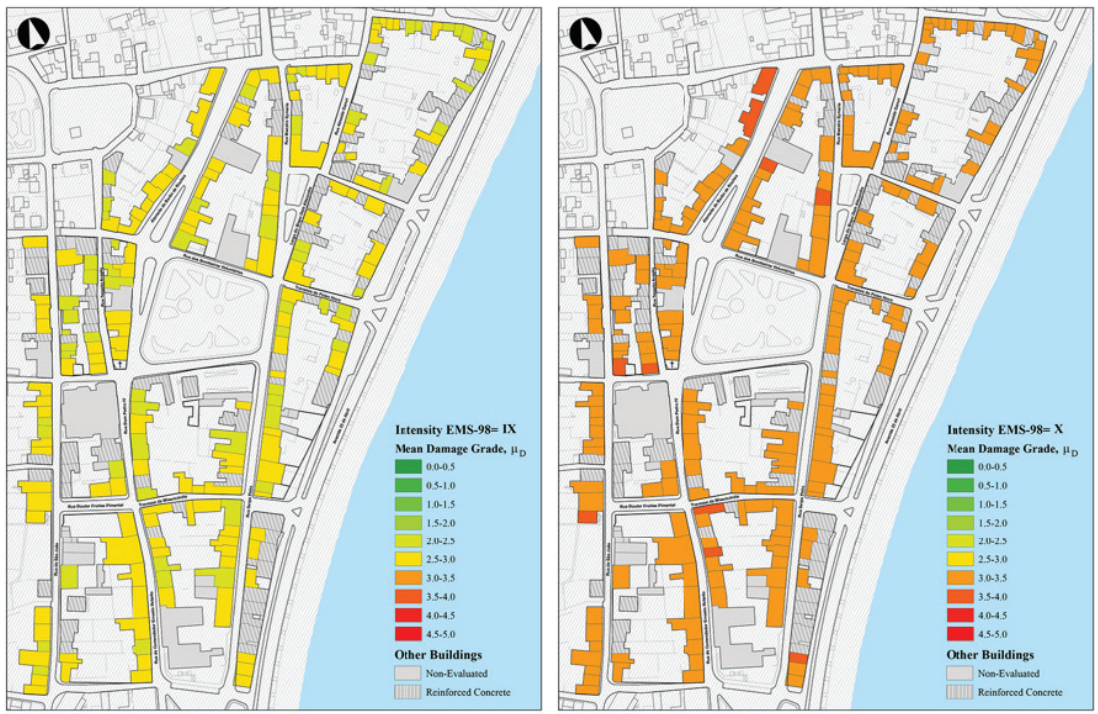

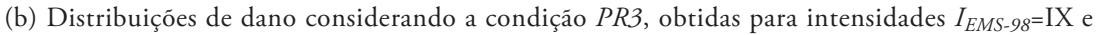
$I_{E M S-98}=\mathrm{X}$

Fig. 8 - Mapeamento do grau de dano médio, , para a condição: (a) $S R$ e (b) após a aplicação do $P R 3$.

Fig. 8 - Mapping of the mean damage grade, , for: (a) SR and (b) PR3 building condition. 
multiplicador variável entre 0 e 1 . Em Itália, o vasto conjunto de informação analisada e tratada por Bramerini et al. (1995) permitiu a aferição dos valores associados a estes factores e a construção das respectivas expressóes analíticas de estimativa de perdas. Neste caso, as expressóes seguintes foram utilizadas, respectivamente, na determinação da probabilidade de colapso e de inutilização dos edifícios.

$$
\begin{gathered}
P_{\text {colapso }}=P\left(D_{5}\right) \\
P_{\text {inutilização do edifício }}=P\left(D_{3}\right) \times W_{\text {ei }, 3}+P\left(D_{4}\right) \times W_{\text {ei }, 4}
\end{gathered}
$$

onde $P\left(D_{i}\right)$ é a probabilidade de ocorrência de um certo grau de dano (de $D_{1}$ a $\left.D_{5}\right)$ e $W_{e i, j}$ são factores multiplicadores que indicam a percentagem de edifícios associados ao grau de dano, $D_{i}$, que sofreram colapso ou, não tendo sofrido colapso, são considerados inutilizáveis. Seguindo o trabalho de Maio et al. (2015a), estes fatores multiplicados foram aqui assumidos como $\mathrm{W}_{\mathrm{ei}, 3}=0.4 \mathrm{We}_{\mathrm{i}, 4}=0.6$. $\mathrm{Na}$ fig. 9 apresentam-se as curvas de probabilidade de colapso e de inutilização dos edifícios para as quatro condiçóes estudadas ( $S R, P R 1, P R 2$ e PR3). Adicionalmente, na TABELA VII sumariam-se os resultados globais obtidos em termos para estas mesmas condiçôes, considerando intensidades macrossísmicas variáveis entre $I_{E M S-98}=$ VIII to $I_{E M S-98}=$ XII.

Tal como no caso anterior, a proposta apresentada pelo Servizio Sísmico Nazionale (SSN) foi aqui utilizada para estimar a probabilidade da ocorrência de mortos, feridos graves e desalojados. No que respeita à probabilidade de mortos e feridos graves, esta foi definida como sendo igual a 30\% do número total dos ocupantes de edifícios colapsados e inutilizáveis. No caso dos sobreviventes (os restantes 70\%), assume-se que é necessário providenciar abrigos temporários para o seu realojamento. As taxas de mortos e feridos graves e de desalojados podem ser determinadas, respectivamente, com recurso às seguintes expressóes:

$$
\begin{gathered}
P_{\text {mortos e feridos graves }}=0.3 \times P\left(D_{5}\right) \\
P_{\text {desalojados }}=P\left(D_{3}\right) \times W_{\mathrm{ei}, 3}+P\left(D_{4}\right) \times W_{\mathrm{ei}, 4}+0.7 \times P\left(D_{5}\right)
\end{gathered}
$$


TABELA VII - Estimativa do número de edifícios colapsados e inutilizáveis, para um total de 192 edifícios avaliados.

TABLE VII - Estimation of the number of collapsed and unusable buildings, for a total of 192 buildings evaluated.

\begin{tabular}{|c|c|c|c|c|}
\hline \multirow{2}{*}{$\begin{array}{l}\text { Intensidade } \\
I_{\text {EMS-98 }}\end{array}$} & \multicolumn{4}{|c|}{ Edifícios colapsados } \\
\hline & $S R$ & PR1 & PR2 & PR3 \\
\hline VIII & 0 & 0 & 0 & 0 \\
\hline IX & $1(0.3 \%)$ & 0 & 0 & 0 \\
\hline $\mathrm{X}$ & $14(7.2 \%)$ & $9(4.7 \%)$ & $8(4.2 \%)$ & $4(2.0 \%)$ \\
\hline XI & $67(34.9 \%)$ & $55(28.6 \%)$ & $52(27.3 \%)$ & $36(18.8 \%)$ \\
\hline XII & $129(67.3 \%)$ & $120(62.4 \%)$ & $118(61.2 \%)$ & $101(52.7 \%)$ \\
\hline \multirow{2}{*}{$\begin{array}{l}\text { Intensidade } \\
I_{\text {EMS-98 }}\end{array}$} & \multicolumn{4}{|c|}{ Edifícios inutilizáveis } \\
\hline & $S R$ & PR1 & PR2 & PR3 \\
\hline VIII & $9(4.5 \%)$ & $6(3.1 \%)$ & $5(2.8 \%)$ & $3(1.5 \%)$ \\
\hline IX & $43(22.4 \%)$ & $35(18.1 \%)$ & $33(17.1 \%)$ & $22(11.5 \%)$ \\
\hline $\mathrm{X}$ & $92(47.7 \%)$ & $85(44.1 \%)$ & $83(43.2 \%)$ & $70(36.4 \%)$ \\
\hline XI & $91(47.3 \%)$ & $96(49.8 \%)$ & $96(50.2 \%)$ & $100(51.8 \%)$ \\
\hline XII & $52(27.1 \%)$ & $59(30.7 \%)$ & $60(31.5 \%)$ & $72(37.3 \%)$ \\
\hline
\end{tabular}

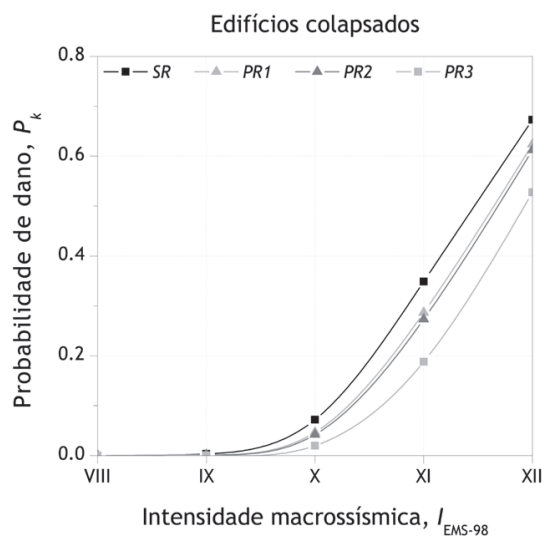

(a)

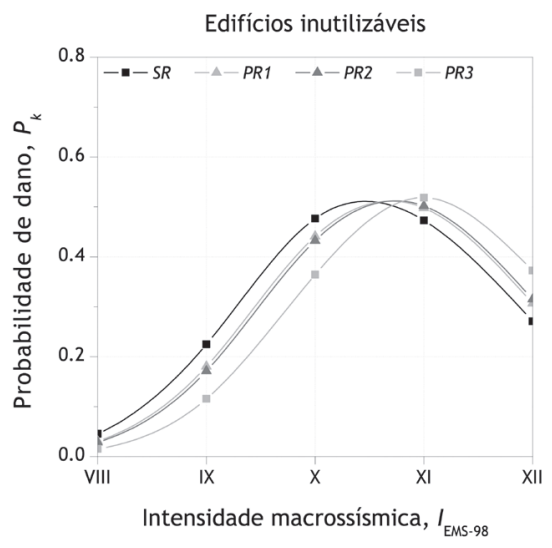

(b)

Fig. 9 - Curvas de probabilidade de colapso (a) e de inutilização de edifícios (b) para as diferentes condiçôes de reforço.

Fig. 9 - Probability of collapsed (a) and unusable buildings (b) for the different building conditions analysed. 
Seguindo o mesmo esquema de apresentação, a fig. 10 apresenta a probabilidade de mortos e feridos graves e de desalojados obtidos para cada uma das condiçóes de reforço analisadas ( $S R$ a $P R 3$ ) e para as mesma intensidades macrossísmicas, entre $I_{E M S-98}=$ VIII e $I_{E M S-98}=X I I$. Adicionalmente, as frequências globais calculadas a partir destes dois outputs probabilísticos encontram-se compiladas na TABela VIII. A propósito das frequências apresentados na TABela VIII importa salientar a reduçáo significativa do número de desalojados em resultado da aplicação das medidas de reforço analisadas. A título de exemplo, refira-se o decréscimo de 15\% no número de desalojados (de 841 para 603, num total de 1596 habitantes), para uma intensidade de $I_{E M S-98}=\mathrm{X}$.

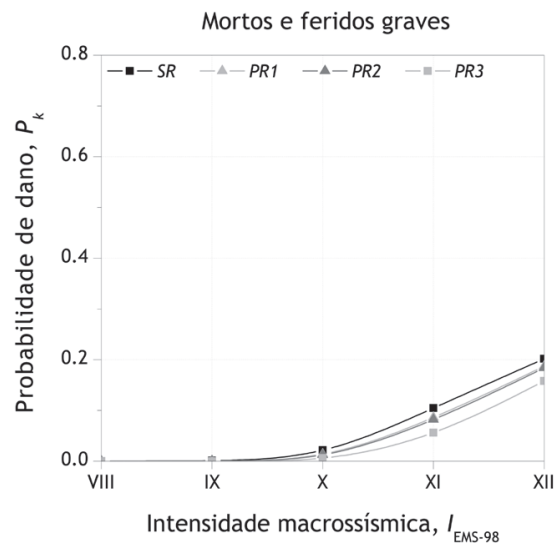

(a)

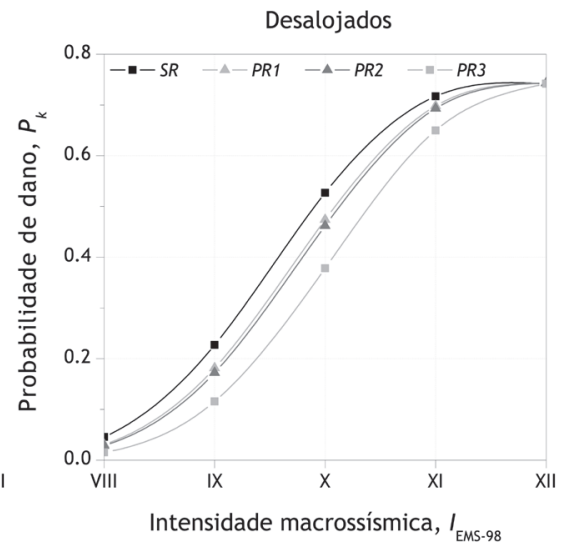

(b)

Fig. 10 - Curvas de probabilidade de mortos e feridos graves (a) e de desalojados (b) para as diferentes condiçóes de reforço analisadas.

Fig. 10 - Probability of deaths and severely injured (a) and homeless (b) for the evaluated building conditions.

Como comentário final, importa salientar o facto de que estes resultados demonstram a importância de uma preparação logística eficiente por parte das autoridades competentes, nomeadamente no realojamento de um número potencial elevado de habitantes (ver TABELA VIII). 
TABELA VIII - Estimativa do número de mortos e feridos e de desalojados, para um total de 1596 habitantes.

TABLE VIII - Estimation of the number of deaths and severely injured and homeless, for a total of 1596 inhabitants.

\begin{tabular}{|c|c|c|c|c|}
\hline \multirow{2}{*}{$\begin{array}{l}\text { Intensidade } \\
\text { IEMS-98 }\end{array}$} & \multicolumn{4}{|c|}{ Mortos e feridos graves } \\
\hline & $S R$ & PRI & $P R 2$ & PR3 \\
\hline VIII & 0 & 0 & 0 & 0 \\
\hline IX & $\begin{array}{c}2 \\
(0.1 \%)\end{array}$ & $\begin{array}{c}1 \\
(0.1 \%)\end{array}$ & $\begin{array}{c}1( \\
0.1 \%)\end{array}$ & 0 \\
\hline $\mathbf{X}$ & $\begin{array}{c}34 \\
(2.2 \%)\end{array}$ & $\begin{array}{c}22 \\
(1.4 \%)\end{array}$ & $\begin{array}{c}20( \\
1.3 \%)\end{array}$ & $\begin{array}{c}9 \\
(0.6 \%)\end{array}$ \\
\hline XI & $\begin{array}{c}167 \\
(10.5 \%)\end{array}$ & $\begin{array}{c}137 \\
(8.6 \%)\end{array}$ & $\begin{array}{c}131 \\
(8.2 \%)\end{array}$ & $\begin{array}{c}90 \\
(5.6 \%)\end{array}$ \\
\hline XII & $\begin{array}{c}322 \\
(20.2 \%) \\
\end{array}$ & $\begin{array}{c}299 \\
(18.7 \%) \\
\end{array}$ & $\begin{array}{c}293 \\
(18.4 \%) \\
\end{array}$ & $\begin{array}{c}253 \\
(15.8 \%) \\
\end{array}$ \\
\hline \multirow{2}{*}{$\begin{array}{l}\text { Intensidade } \\
\mathrm{I}_{\mathrm{EMS}-98}\end{array}$} & \multicolumn{4}{|c|}{ Desalojados } \\
\hline & $S R$ & PR1 & PR2 & PR3 \\
\hline VIII & $\begin{array}{c}73 \\
(4.5 \%)\end{array}$ & $\begin{array}{c}49 \\
(3.1 \%)\end{array}$ & $\begin{array}{c}45 \\
(2.8 \%)\end{array}$ & $\begin{array}{c}24 \\
(1.5 \%)\end{array}$ \\
\hline IX & $\begin{array}{c}363 \\
(22.7 \%)\end{array}$ & $\begin{array}{c}290 \\
(18.2 \%)\end{array}$ & $\begin{array}{c}275 \\
(17.2 \%)\end{array}$ & $\begin{array}{c}185 \\
(11.6 \%)\end{array}$ \\
\hline $\mathbf{x}$ & $\begin{array}{c}841 \\
(52.7 \%)\end{array}$ & $\begin{array}{c}756 \\
(47.4 \%)\end{array}$ & $\begin{array}{c}737 \\
(46.2 \%)\end{array}$ & $\begin{array}{c}603 \\
(37.8 \%)\end{array}$ \\
\hline XI & $\begin{array}{c}1144 \\
(71.7 \%)\end{array}$ & $\begin{array}{c}1114 \\
(69.8 \%)\end{array}$ & $\begin{array}{c}1106 \\
(69.3 \%)\end{array}$ & $\begin{array}{c}1037 \\
(65.0 \%)\end{array}$ \\
\hline XII & $\begin{array}{c}1184 \\
(74.2 \%)\end{array}$ & $\begin{array}{c}1186 \\
(74.3 \%)\end{array}$ & $\begin{array}{c}1187 \\
(74.4 \%)\end{array}$ & $\begin{array}{c}1184 \\
(74.2 \%)\end{array}$ \\
\hline
\end{tabular}

\section{Perdas económicas}

Nesta secção, o desempenho de cada uma das açóes de reforço consideradas neste trabalho é analisa, não apenas do ponto de vista do seu efeito na redução da vulnerabilidade sísmica do edifício, mas também do ponto de vista da sua viabilidade económica. Segundo Benedetti e Petrini (1984), o grau de dano médio, discutido na secção anterior, pode ser interpretado quer economicamente, quer em termos de um índice económico traduzido no rácio entre o custo de reparação e o custo de reposição (isto é, o valor do edifício). A correlação entre 
o grau de dano médio e estes dois custos foi proposta por Dolce et al. (2006) com base na análise de informação de dano pós-sismo recolhida com recurso à metodologia GNDT-SSN (1994), após os sismos de Umbria-Marche (1997) e de Pollino (1998). Tirando partido da quantidade extensiva de informaçáo recolhida e analisada, estes autores obtiveram valores estatísticos baseados na estimativa do custo associado a açóes de reparação padrão aplicadas a um universo de mais de 50000 edifícios.

Assim, e de acordo com Vicente et al. (2010), a probabilidade associada ao custo de reparação para um determinado evento sísmico caracterizado por uma intensidade $I, P[R \mid I$, pode ser obtido através do produto entre a probabilidade condicionada do custo de reparação para cada nível de dano, $P\left[R \mid D_{K}\right]$, e a probabilidade condicionada da condição de dano para cada edifício sujeito a uma determinada intensidade sísmica, $\mathrm{P}\left[D_{k} \mid I_{v}, I\right.$ :

$$
P[R \mid l]=\sum_{D_{\mathrm{k}}=1}^{5} \sum_{l_{\mathrm{v}}=0}^{100} P\left[R \mid D_{\mathrm{k}}\right] \times P\left[D_{\mathrm{k}} \mid I_{V}, I\right]
$$

Para estimar os custos de reposição associados às diferentes condiçóes de reforço, foi adoptado um valor médio de $700 € / \mathrm{m}^{2}$ para o edificado antigo no centro histórico da cidade da Horta, valor que se encontra em linha com o estimado por Dolce et al. (2006) a partir do processo de reconstrução conduzido após o terramoto de Irpinia. De forma a entrar em linha de conta com o valor patrimonial do edificado, e uma vez que a adopção de técnicas e materiais tradicionais podem aumentar ligeiramente os custos associados ao processo, o valor médio considerado para os edifícios na situação $S R$ foi corrigido para $1000 € / \mathrm{m}^{2}$. Vale a pena notar que este valor foi já sugerido no passado por Vicente et al. (2011) para a cidade portuguesa de Coimbra.

Com base neste valores probabilísticos é então possível estimar o custo global de reposição do edificado contido na área em estudo (192 edifícios) e obter o balanço económico calculado para cada uma dos três pacotes de reforço sísmico considerados em relação à situação inicial $S R$. Este resultado encontra-se ilustrado na fig. 11 para intensidades macrossísmicas entre $I_{\mathrm{EMS}-98}=\mathrm{V}$ e XII, encontrando- 
-se ainda sistematizado na TABELA IX sob a forma de valores poupança global associados a este balanço económico. Adicionalmente, os períodos médios de inatividade sísmica referidos por Nunes (2008) para o Arquipélago dos Açores (isto é, a quantidade média de tempo entre dois terramotos de intensidades de $\mathrm{V}<I_{\text {EMS-98 }}<$ VIII e $I_{\text {EMS-98 }} \geq$ VIII), foram ainda incluídos na fig. 11 com o objetivo de facilitar a interpretação e a análise dos resultados que aqui se discutem.

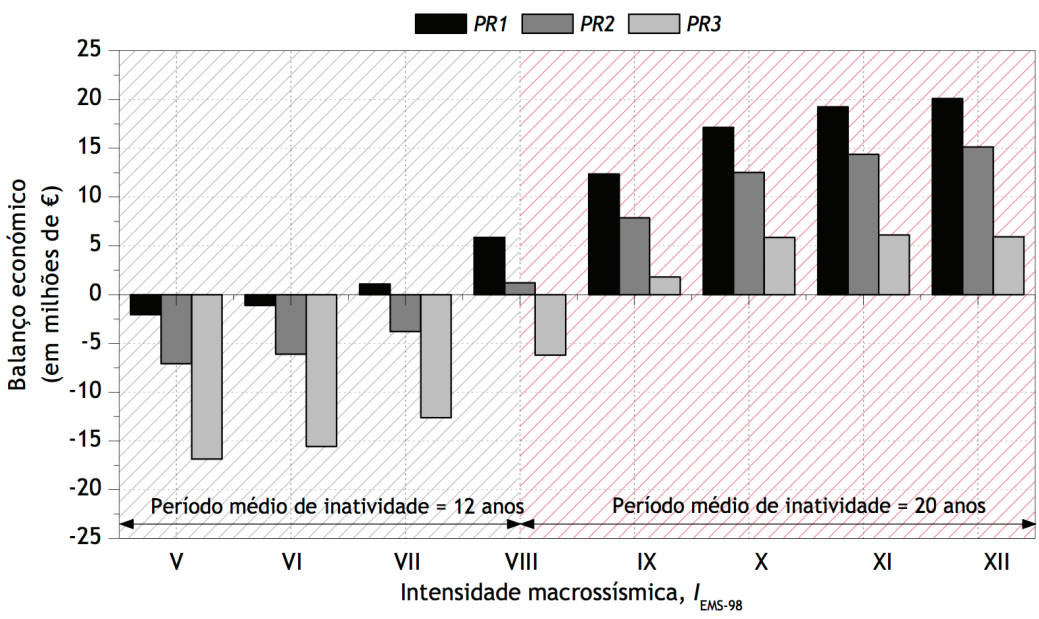

Fig. 11 - Balanço económico obtido para as três condições de reforço consideradas em relação à condição inicial $S R$.

Fig. 11 - Economic balance for the three retrofitting packages considered, in relation to the SR building condition.

Da análise da fig. 12 é fácil concluir que os três pacotes de reforço analisados provaram ser viáveis economicamente para intensidades macrossísmicas iguais ou superiores a IX. Apesar deste facto, para as intensidades $I_{\text {EMS-98 }}=$ VII e VII, as quais se encontram já dentro do período médio de inatividade de 12 anos, foram obtidas poupanças globais da ordem dos 1.08 e 5.85 milhóes de euros (M€) com a aplicação dos pacotes de reforço PR1 e PR2, respetivamente (ver TABEla IX).

Como seria de prever, as poupanças globais obtidas são mais expressivas para intensidades mais elevadas, uma vez que o nível relativo de dano sofrido 
pelos edifícios é mais importante para essa intensidades, o que leva a que, do ponto de vista estritamente económico, o pacote de reforço $P R 1$ tenha sido o mais eficiente em termos económicos, com poupanças globais da ordem dos $20 \mathrm{M} €$. No entanto, é importante sublinhar que estes resultados devem ser analisados e interpretados lado a lado com os resultados de dano e de perdas apresentados na secçáo anterior, uma vez que, apesar dos pacotes $P R 2$ e $P R 3$, para determinadas intensidades, serem menos interessantes do ponto de vista económico, a sua aplicação conduz a um decréscimo significativo em termos de perdas humanas. Dê-se como exemplo o pacote $P R 2$, com um custo estimado de $100 € / \mathrm{m}^{2}$, isto é, cerca de $14 \%$ do valor médio do custo de reposição, e que conduz a uma reduçấo de cerca de $0.9 \%, 6.5 \%, 3.0 \%$ e $4.5 \%$ em termos de mortos e feridos graves, desalojados, edifícios colapsados e edifícios inutilizáveis, para uma intensidade $I_{\mathrm{EMS}-98}=\mathrm{X}$. Replicando o exercício para o pacote de reforço PR3, com um custo estimado de cerca de $33 \%$ do custo médio de reposiçáo, é possível obter uma redução da ordem dos $51.7 \%$ em termos do valor global do índice de vulnerabilidade sísmica, o que, em termos de estimativa de danos para uma intensidade $I_{\text {EMS-98 }}=\mathrm{X}$, corresponde a uma redução de 1.6\%, 14.9\%, $5.0 \%$ e $11.5 \%$ em termos de rácios de mortos e feridos, desalojados, edifícios colapsados e edifícios inutilizáveis.

Finalmente, note-se que ao longo do processo de reconstrução e reforço do edificado da ilha do Faial atingido pelo terramoto de intensidade VIII que abalou o Arquipélago dos Açores em 1998, foi gasto um total de 330 milhóes de euros, valor que representa aproximadamente 1/6 do Produto Interno Bruto

TABELA IX - Poupanças globais obtidas através de cada um dos pacotes de reforço analisados $P R_{i}$ (em milhoóes de $€$ ).

TABLE IX - Global savings obtained for each retrofitting package $P R_{i}$ (in millions of $€$ ).

\begin{tabular}{ccccccccc}
\hline \multirow{2}{*}{$\begin{array}{c}\text { Pacote } \\
\text { de } \\
\text { reforço }\end{array}$} & \multicolumn{7}{c}{ Intensidade macrossísmica, I IMS-98 } \\
\cline { 2 - 9 } & $\mathbf{V}$ & VI & VII & VIII & IX & X & XI & XII \\
\hline$P R 1$ & - & - & 1.08 & 5.85 & 12.24 & 17.15 & 19.23 & 20.10 \\
$P R 2$ & - & - & - & 1.20 & 7.89 & 12.53 & 14.39 & 15.13 \\
$P R 3$ & - & - & - & - & 1.80 & 5.86 & 6.12 & 5.91 \\
\hline
\end{tabular}


da Região Autónoma dos Açores. Assim, é fácil perceber que caso alguma destas açóes de reforço tivesse sido estudada e implementada antes do terramoto, os custos associados à sua implementação seriam praticamente desprezáveis quando comparados com o valor total despendido no referido processo de reconstrução, tendo sido ainda possível reduzir drasticamente as perdas materiais e humanas associadas ao evento.

\section{Conclusão}

As conclusóes e recomendaçóes mais gerais que se retiram do trabalho desenvolvido vão ao encontro da necessidade de melhorar a perceção pública, educação e investigação relacionada com a mitigação do risco sísmico, aproveitando os diversos veículos e agentes de comunicação disponíveis na nossa sociedade. Idealmente, as estratégias de mitigação de risco devem abranger a redução da exposição das comunidades e um planeamento e desenvolvimento urbano mais sustentável, assim como campanhas de reforço sísmico aplicadas em conformidade com uma legislação competente e responsável, que garanta simultaneamente reforçar condignamente o edificado existente e exigir um adequado dimensionamento sísmico em construçóes novas. Se forem revistas as atuais políticas em torno desta temática e repensados os modelos de apoio financeiro e institucional, tanto numa escala regional como nacional, será possível reduzir a vulnerabilidade sísmica do nosso edificado de forma sustentável e sem custos desmesuráveis para ambas as partes interessadas.

Tal como esperado, os resultados obtidos em termos de perdas e danos para o núcleo urbano antigo da cidade da Horta não resultaram tão gravosos como em outros casos de estudo anteriores (caso do Bairro Ribeirinho de Faro), isto porque o índice de vulnerabilidade médio do edificado apresenta uma grande influência sobre as formulaçóes aqui utilizadas para tais estimativas. Ainda assim, estes resultados podem dizer-se bem ajustados ao dano observado em toda a área de estudo, decorrente do terramoto dos Açores de 1998. 
Relativamente à implementação das soluçóes de reforço consideradas, estas conduziram a uma melhoria significativa do desempenho sísmico global do edificado, traduzido pela melhoria dos valores do índice de vulnerabilidade sísmica, refletindo de forma satisfatória a sua real influência sobre a capacidade de resistência ao corte, ductilidade e comportamento em caixa dos edifícios. No entanto, uma vez mais, os resultados em termos de reduçáo de perdas poderiam ter sido mais expressivos caso tivessem sido atingidos valores mais elevados nos índices de vulnerabilidade sísmica na condição original $S R$ dos edifícios. Não obstante, aplicação da solução de reforço $S 5$, relativa à melhoria da ligação entre paredes e cobertura através de cintas de coroamento, fez levantar algumas questôes sobre o seu contributo efetivo no desempenho sísmico global do edifício. Alguns autores defendem que esta técnica, apesar de bastante comum no edificado da Horta, poderá favorecer o desenvolvimento de mecanismos de colapso nas paredes resistentes quando sujeitas uma excitação sísmica, devido a um importante aumento de massa e rigidez, localizado no topo das paredes, podendo introduzir modificaçóes importantes nos modos de vibração da estrutura, especialmente em edifícios com dois ou mais pisos. Assim, os autores sugerem que este tipo de soluçấo seja revisto e examinado sob o ponto de vista mecânico, numérico e experimental, de forma esclarecer esta questão.

Finalmente, no que diz respeito às perdas económicas, é importante sublinhar que os três pacotes de reforço considerados neste estudo apresentaram uma boa relação custo-benefício para as intensidades macrossísmicas mais elevadas ( $I_{E M S-98}=\mathrm{IX}$ a XII), permitindo atingir poupanças globais na ordem dos 20 M€. Por outro lado, para intensidades moderadas ( $I_{E M S-98}=\mathrm{VII}$ a VIII), foram estimadas poupanças ainda assim muito interessantes de 5.85 e $1.20 \mathrm{M} €$ com a aplicaçáo dos pacotes de reforço $P R 1$ e $P R 2$, respetivamente.

\section{Agradecimentos}

Este trabalho foi financiado pela Fundação para a Ciência e Tecnologia (FCT), desenvolvido ao abrigo do projeto de investigação URBSIS - Avaliação 
da Vulnerabilidade e Gestáo do Risco Sísmico à Escala Urbana (PRDC/ECMURB/2564/2012). Os autores agradecem à SPRIH, à REg, ao Eng. ${ }^{\circ}$ Filipe Neves e ao Prof. Aníbal Costa pela disponibilização de um conjunto de informaçáo relacionada com o processo de reconstruçáo da ilha do Faial, fundamental para a realização deste estudo.

\section{Referências bibliográficas}

Arshad, Shahnaz e Athar, Sohaib (2013). Rural Housing Reconstruction Program Post-2005 Earthquake - Learning from the Pakistan Experience - A Manual for Post-Disaster Housing Program Managers. The World Bank Group, pp 116 (em inglês).

Astroza, Maximiliano; Ruiz, Sergio e Astroza, Rodrigo (2012). Damage Assessment and Seismic Intensity Analysis of the 2010 (Mw 8.8) Maule Earthquake. Earthq Spectra 28:S145-S164.

Benedetti, Duilio e Petrini, Vicenzo (1984). Sulla vulnerabilita sismica di edifici in muratura: un metodo di valutazione. A method for evaluating the seismic vulnerability of masonry buildings. L'industria delle Costruzioni, pp 66-74 (em italiano).

Bernardini, Alberto; Giovinazzi, Sonia; Lagomarsino, Sergio e Parodi, Sonia (2007). Vulnerabilità e previsione di danno a scala territoriale secondo una metodologia macrosismica coerente con la scala EMS-98. In 12th Conf. Ital. Natl. Assoc. Earthq. Eng. - ANIDIS. 10-14 Giugno, Pisa, Italia (em italiano).

Bothara, Jithendra e Brzev, Svetlana (2011). A TUTORIAL: Improving the Seismic Performance of Stone Masonry Buildings, $1^{\text {st }}$ ed. EERI, Oakland, California, USA. ISBN: 9781932884487 (em inglês).

Bramerini, Fabrizio; Di Pasquale, Giacomo; Orisini, A. ; Pugliese, A. ; Romeo, R. e Sabetta, Fabio (1995). Rischio sismico del territorio Italiano: proposta per una metodologia e risultati preliminary, Technical report SSN/RT/95/01. Servizio Sismico Nazionale. Roma, Italia (em italiano).

Calvi, G. Michele; Pinho, Rui; Magenes, Guido; Bommer, Julian J.; Restrepo-Vélez, L. Fernando and Crowley, Helen (2006). Development of seismic vulnerability assessment methodologies over the past 30 years. ISET Journal of Earthquake Technology, Paper No. 472, Vol. 43, No. 3, September 2006, pp. 75-104 (em inglês).

Carreño, Martha-Liliana; Cardona, O. Darío e Barbat, Alex (2007). Urban Seismic Risk Evaluation: A Holistic Approach. Nat Hazards 40:137-172. doi:10.1007/s11069-006-0008-8.

Carvalho, E. Cansado; Oliveira, C. Sousa; Fragoso, Mário e Miranda, Vidália (1998). Regras gerais de reabilitação e reconstrução de edifícios correntes afectados pela crise sísmica do Faial, Pico e São Jorge, iniciada pelo sismo de 9 de Julho de 1998. LREC/DMCE REl. 100/98.

Coaffee, Jon (2008). Risk, resilience, and environmentally sustainable cities. Energy Policy 36:4633-4638. doi:10.1016/j.enpol.2008.09.048 (em inglês).

Costa, Aníbal (2002). Determination of mechanical properties of traditional masonry walls in dwellings of Faial Island, Azores. Earthq Eng Struct Dyn 31:1361-1382. doi:10.1002/eqe.167 (em inglês). 
Costa, Aníbal; Oliveira, C. Sousa e Neves, Filipe (2008). Reinforcing techniques more commonly used in Faial reconstruction. Sismo 1998 - Açores. Uma década depois, 1st ed. pp 531-555.

Costa, A. Aníbal; Arêde, António; Costa, Aníbal; Guedes, João e Silva, Bruno (2012). Experimental testing, numerical modelling and seismic strengthening of traditional stone masonry: comprehensive study of a real Azorian pier. Bull Earthq Eng 10:135-159. doi:10.1007/s10518010-9209-3 (em inglês).

D’Ayala, Dina; Spence, Robin; Oliveira, C. Sousa e Pomonis, Antonios (1997). Earthquake Loss Estimation for Europe's Historic Town Centres. Earthq Spectra 13:773-793. doi: $10.1193 / 1.1585980$ (em inglês).

D’Ayala, Dina e Speranza, Elena (2002). Housing Report: Single-family stone masonry house. Earthquake Engineering Research Institute (EERI) and International Association for Earthquake Engineering (IAEE), pp 15 (em inglês).

Dolce, Mauro; Kappos, Andreas; Masi, Angelo; Penelis, Gregory e Vona, Marco (2006). Vulnerability Assessment and Earthquake Damage Scenarios of the Building Stock of Potenza (Southern Italy) using Italian and Greek Methodologies. Elsevier - Eng Struct 28:357-371. doi:10.1016/j. engstruct.2005.08.009 (em inglês).

Esri (2012). Environmental Systems Research Institute, Inc. (ESRI). 310 New York Street, Redlands, 92373-8100, USA.

Ferreira, T. Miguel; Vicente, Romeu; Mendes da Silva, J. A. Raimundo; Varum, Humberto e Costa, Aníbal (2013). Seismic vulnerability assessment of historical urban centres: case study of the old city centre in Seixal, Portugal. Bull Earthq Eng 11:1753-1773. doi:10.1007/s10518-0139447-2 (em inglês).

GNDT (1994). Scheda di esposizione e vulnerabilità e di rilevamento danni di primo livello e secondo livello (muratura e cemento armato). Grupo Nazionale per la Difesa dai Terrmoti Servizio Sismico Nazionale, Rome, Italy (em italiano).

Goula, Xavier; Roca, Antoni e Oliveira, C. Sousa (2006). Assessing and managing earthquake risk - Geo-Scientific and Engineering Knowledge for Earthquake Risk Mitigation: developments, tools, techniques. Springer. 2nd editon; ISBN: 978-1-4020-3524-1, pp 564 (em inglês).

Gregersen, Søren; Basham, Peter e Moreira V. S. (1989). Earthquakes at North-Atlantic Passive Margins: Neotectonics and Postglacial Rebound. Seism. Port. Cont. Margin, NATO ASI S. Springer Netherlands, pp 533-545 (em inglês).

Grünthal, Gottfried (1998) European Macroseismic Scale 1998 (EMS-98). European Seismological Commission, Subcommission on Engineering Seismology, Working Group Macroseismic Scales. Cahiers du Centre Européen de Géodynamique et de Séismologie, pp 15:101 (em inglês).

Maio, Rui; Ferreira, T. Miguel; Vicente, Romeu e Estêvão, João (2015a). Seismic vulnerability assessment of historical centres: case study of the old city centre of Faro, Portugal. J Risk Res. doi: 10.1080/13669877.2014.988285 (em inglês).

Maio, Rui; Ferreira T. Miguel e Vicente, Romeu (2015b). The morphology of old urban centres: architectural and constructive survey of Bairro Ribeirinho of Faro, Portugal. Conservar Património. doi: 10.14568/cp2015002.

Mitchelson, Mark (2011). Haiti and Christchurch Earthquakes Viewed through a resilience lens - A comparative case study. Tese de Mestrado em Emergency Management (MEmMgt). Auckland University of Technology. pp 92 (em inglês).

Neves, Filipe; Costa, Aníbal; Vicente, Romeu; Oliveira, C. Sousa e Varum, Humberto (2012). Seismic vulnerability assessment and characterisation of the buildings on Faial Island, Azores. Bull Earthq Eng 10:27-44. doi: 10.1007/s10518-011-9276-0 (em inglês). 
Neves, Nuno; Arêde, António e Costa, Aníbal (2012). Seismic analysis of a building block. Bull Earthq Eng. doi:10.1007/s10518-011-9310-2. pp 1-33 (em inglês).

NTC (2008). Ministero dei Lavori Pubblici, Decreto Ministeriale 14/1/2008, Norme tecniche per le costruzioni (em italiano).

Nunes J. Carlos (2008). General description of the Azores region seismicity. Sismo 1998 - Açores. Uma década depois, 1st Edition. Horta, Faial Island, Azores, Portugal, pp 59-72.

Oliveira, C. Sousa; Lucas, Arcindo e Guedes, J. H. Correia (1990). MONOGRAFIA - 10 Anos após o Sismo dos Açores de 1 de Janeiro de 1980 - Volume I e II. Secretaria Regional da Habitação e Obras Públicas, Delegação da Ilha Terceira, Açores, Laboratório Nacional de Engenharia Civil, Angra do Heroísmo, Açores, Portugal.

Pagnini, L. Carlotta; Vicente, Romeu; Lagomarsino, Sergio e Varum, Humberto (2011). A mechanical model for the seismic vulnerability assessment of old masonry buildings. Earthq Struct 2:25-42 (em inglês).

Ranghieri, Federica e Ishiwatari, Mikio (eds) (2014). Learning from Megadisasters - Lessons from the Great East Japan Earthquake. The World Bank Group. doi:10.1596/978-1-4648-0153-2. pp 391 (em inglês).

Silva, Vitor; Crowley, Helen; Varum, Humberto e Pinho, Rui (2014). Seismic risk assessment for mainland Portugal. Bull Earthq Eng. doi:10.1007/s10518-014-9630-0 (em inglês).

Vicente, Romeu (2008). Estratégias e metodologias para intervençóes de reabilitação urbana Avaliação da Vulnerabilidade e do Risco Sísmico do Edificado da Baixa de Coimbra. Tese de Doutoramento. Departamento de Engenharia Civil da Universidade de Aveiro. pp 471.

Vicente, Romeu; Ferreira, T. Miguel; Maio, Rui e Koch, Herbert (2014a). Awareness, Perception and Communication of Earthquake Risk in Portugal: Public Survey. Procedia Econ Financ 18:271-278. doi:10.1016/S2212-5671(14)00940-X (em inglês).

Vicente, Romeu; Ferreira, T. Miguel; Maio, Rui (2014b). Seismic Risk at the Urban Scale: Assessment, Mapping and Planning. Procedia Econ Financ 18:71-80. doi:10.1016/S22125671(14)00915-0 (em inglês).

Vicente, Romeu; Parodi, Sonia; Lagomarsino, Sergio; Varum, Humberto e Mendes da Silva, J. A. Raimundo (2011). Seismic vulnerability and risk assessment: case study of the historic city centre of Coimbra, Portugal. Bull Earthq Eng 9:1067-1096. doi:10.1007/s10518-010-92333 (em inglês).

Vicente, Romeu; Mendes da Silva, J. A. Raimundo; Varum, Humberto; Costa, Aníbal; Oliveira, C. Sousa; Ferreira, T. Miguel; Santos, Mário; Santos, Cátia e Subtil, Ana (2010) Avaliação da vulnerabilidade sísmica do núcleo urbano antigo do Seixal. In 8th Port Congr Seismol Seism Eng.

Zonno, G ; Oliveira, C. Sousa; Ferreira, Mónica Amaral ; Musacchio, G. ; Meroni, F. ; Mota-deSá, Francisco e Neves, Filipe (2010). Assessing Seismic Damage Through Stochastic Simulation of Ground Shaking: The Case of the 1998 Faial Earthquake (Azores Islands). Springer - Surv Geophys 31:361-381. doi:10.1007/s10712-009-9091-1 (em inglês). 